\title{
The evolution of life cycle assessment in European policies over three decades
}

\author{
Serenella Sala ${ }^{1,2}$ (]) $\cdot$ Andrea Martino Amadei ${ }^{1} \cdot$ Antoine Beylot $^{2} \cdot$ Fulvio Ardente $^{1}$
}

Received: 22 December 2020 / Accepted: 18 March 2021 / Published online: 20 April 2021

(c) The Author(s) 2021, corrected publication 2021

\begin{abstract}
Purpose Life cycle thinking (LCT) and life cycle assessment (LCA) are increasingly considered pivotal concept and method for supporting sustainable transitions. LCA plays a relevant role in decision support, for the ambition of a holistic coverage of environmental dimensions and for the identification of hotspots, possible trade-offs, and burden shifting among life cycle stages or impact categories. These features are also relevant when the decision support is needed in policy domain. With a focus on EU policies, the present study explores the evolution and implementation of life cycle concepts and approaches over three decades.

Methods Adopting an historical perspective, a review of current European Union (EU) legal acts and communications explicitly mentioning LCT, LCA, life cycle costing (LCC), and environmental footprint (the European Product and Organisation Environmental Footprint PEF/OEF) is performed, considering the timeframe from 1990 to 2020. The documents are categorised by year and according to their types (e.g. regulations, directives, communications) and based on the covered sectors (e.g. waste, energy, buildings). Documents for which life cycle concepts and approaches had a crucial role are identified, and a shortlist of these legal acts and communications is derived.

Results and discussion Over the years, LCT and life cycle approaches have been increasingly mentioned in policy. From the Ecolabel Regulation of 1992, to the Green Deal in 2019, life cycle considerations are of particular interest in the EU. The present work analysed a total of 159 policies and 167 communications. While in some sectors (e.g. products, vehicles, and waste) life cycle concepts and approaches have been adopted with higher levels of prescriptiveness, implementation in other sectors (e.g. food and agriculture) is only at a preliminary stage. Moreover, life cycle (especially LCT) is frequently addressed and cited only as a general concept and in a rather generic manner. Additionally, more stringent and rigorous methods (LCA, PEF/OEF) are commonly cited only in view of future policy developments, even if a more mature interest in lifecycle is evident in recent policies.

Conclusion The EU has been a frontrunner in the implementation of LCT/LCA in policies. However, despite a growing trend in this implementation, the development of new stringent and mandatory requirements related to life cycle is still relatively limited. In fact, there are still issues to be solved in the interface between science and policy making (such as verification and market surveillance) to ensure a wider implementation of LCT and LCA.
\end{abstract}

Keywords Life cycle thinking · Life cycle assessment · European Union · Policy · Legal acts · Environmental footprint · Communication

\section{Introduction}

Communicated by Matthias Finkbeiner.

Serenella Sala

serenella.sala@ec.europa.eu

1 European Commission - Joint Research Centre, Ispra, VA, Italy

2 BRGM - Bureau de Recherches Géologiques et Minières, Orléans Cedex 2, France
The transition towards sustainability poses huge challenges to policy making, especially for what concerns comprehensive assessment of impacts and trade-offs between environmental pressures and impacts and measures to limit them. Policy makers are increasingly confronted with multifaceted challenges, in which environmental and socio-economic issues should be considered simultaneously and in which 
the threats posed by the economic crises should be turned into positive actions towards sustainability.

Life cycle thinking (LCT) is a systemic and comprehensive concept considered pivotal to provide support in better integrating sustainability into policy making (Pennington et al. 2007; Sonnemann et al. 2018). LCT is the basic concept referring to the needs of assessing burdens of products/ sectors/projects adopting a holistic perspective, from raw material extraction to end of life. LCT aims at avoiding the shift of burdens between environmental impact categories (e.g. reducing climate change while increasing land use), shifting between world regions (e.g. reducing domestic impacts while increasing spill-over effects), or between life cycle stages (e.g. decreasing impacts during the manufacturing of a product while increasing the impacts due to the end of life management) (Sala 2019).

LCT is at the core of the Sustainable Development Goal (SDG) 12 of the UN Agenda 2030, "responsible consumption and production" that aims at the adoption of more sustainable patterns of consumption by the year 2030 and whose achievement needs a significant focus on the supply chain from producers to final consumers (UN 2015).

According to the definition reported in the ISO standard (ISO 2006a), life cycle assessment (LCA) is the compilation and evaluation of the inputs, outputs, and the potential environmental impacts of a product system throughout its life cycle. LCA builds on a life cycle thinking perspective to provide valuable comprehensive quantitative information on the environmental performance of goods and services, and it can be effective to assess and support sustainable production and consumption (SCP), in particular as scientific basis for policies on products design, consumer information, public procurement, waste management, energy, and food supply (Sonnemann et al. 2018). However, a number of barriers still limit the use of LCA in policies, as the lack of widespread technical knowledge on LCA, and the lack of trust in LCA process and results (Seidel 2016). Moreover, to be enforceable in the context of entry market instruments, life cycle-based requirements need to also be verifiable by market surveillance authorities, e.g. through standardised methods (Mathieux et al. 2020). Flaws and variability in LCA studies, in particular in the interpretation phase, may both mislead and reduce the trust of policy makers in LCA (Agostini et al, 2020).

Together with LCT and LCA, life cycle costing (LCC) is being applied by an increasing number of public authorities across the EU and in a range of sectors (EU, 2020a). LCC is defined as an "economic assessment considering all agreed projected significant and relevant cost flows over a period of analysis expressed in monetary value. The projected costs are those needed to achieve defined levels of performance, including reliability, safety and availability" (ISO 2017). The role of LCC is especially relevant in the context of sustainable public procurement, for demonstrating the best value for money and for governments, since the integration of LCC into policies is emerging as a relevant approach for comparing "green" and socially preferable assets with their less sustainable substitutes (Perera et al. 2009).

Although facing key challenges, LCT and LCA have been increasingly implemented in policies around the world in the last three decades (Sonnemann et al. 2018). Over time some studies were developed to assess the level of implementation of LCA in policies (e.g. Curran 1997, Sonneman et al. 2018), in some cases focusing on specific cases (e.g. for EU, Sala et al. 2016, for USA, Schenck et al. 2009, or Japan, Hunkeler et al. 1998). Other studies focused on the specific needs of the LCA for policies, namely whether these needs are different from LCA used for assessment of product performance (Waardenaar et al. 2012), including the appropriateness of modelling approaches (e.g. whether consequential or attributional fit better the purposes as in Vázquez-Rowe et al. (2014) or Brander et al. (2008). Moreover, the role of LCA in sectorial policies was assessed, e.g. for waste as in Lazarevic et al. (2012) or in development policies as in Kituyi (2004). As of today, a number of regulations using LCT and LCA are implemented in several distinct regions of the globe. LCA has been applied in policy development and implementation in several countries, including the USA (through the Energy Independence and Security Act of 2007 (EPA 2020); Reed 2012), China (e.g. promoting the use of LCA in product design; Sonnemann et al. 2018), and Thailand (e.g. implementing LCA to assess the Thai Green Procurement Plan; Sonnemann et al. 2018). Latin America and the Caribbean region have developed its SCP strategy since 2003 and are considered a pioneer on SCP by the United Nations Environment Programme (UNEP 2015). Mexico, Chile, Colombia, and Brazil have used LCA in several policies, in a context of emerging awareness of policy-makers in these emerging economies (Valdivia et al. 2017; Maia de Souza et al. 2017; Güereca et al. 2015). However, the EU has been in the forefront in using LCA into development and application to a much larger extent than in any other region in the world (Sonnemann et al. 2018; Reed 2012). Current European initiatives on building life cycle-based policies are observed with attention from other parts of the globe, as stated, e.g. by Maia de Souza et al. (2017) for Brazil.

In June 2001, the European Commission (EC) published the communication on Integrated Product Policy (IPP) (CEC 2001). This communication had a crucial role in paving the path for the development of policies including life cycle concepts, recognising life cycle thinking as an element contributing to sustainable development and science-based decision making. In December 2005, life cycle thinking exhibited a pivotal role as an indicator to monitor decoupling economic growth from environmental impacts in the Thematic Strategy on the Sustainable Use of Natural Resources 
(CEC 2005a). In parallel, the Thematic Strategy on the Prevention and Recycling of Waste (CEC 2005b) proposed an amendment (CEC 2005c) of the 1975 Waste Framework Directive (EC 1975) in view of introducing life cycle thinking for assessing environmental impacts of the generation and management of waste. These communications and legal acts were the basis for the implementation of life cycle concepts in European policies in the year 2000s. In particular, the Ecolabel Regulation (EC 1992, 2010a) and the Ecodesign Directive (EC 2005, 2009a) constitute relevant LCA application in policies: the former aiming at establishing a voluntary ecolabel award scheme to promote products with reduced life cycle environmental impacts and the latter aiming at establishing consistent EU-wide rules for improving the environmental performance of energy-related products through ecodesign. The Ecodesign Directive was also a first worldwide example of the introduction of mandatory requirements for new products following on a life cycle approach, including the possibility of setting generic requirements based on the so-called "ecological profile." A milestone in the development of policies based on LCA was the 2013 communication "Building the Single Market for Green Products" (CEC 2013a) and the linked Recommendation (EC 2013a), establishing the Product- and Organisation-Environmental Footprint methods (respectively, PEF and OEF). These LCA-based methods aim at the quantification of the environmental impacts of products and organisations, improving replicability, robustness and transparency of LCA studies. In fact, the PEF/OEF methods introduced an important improvement and guidance compared to the existing LCA standards (ISO 2006a, b) concerning key methodological choices and data quality requirements, and overall contributed to the comparability and verifiability of green claims by companies. Recently, the concept of life cycle has been at the centre of relevant policies (in sectors such as packaging and packaging waste (EC 2018a), vehicles (EC 2019a), and plastic (EC 2019b)) and communications (as for instance the European Green Deal (CEC 2019a), the Circular Economy Action Plan (CEC 2020a), and the Farm to Fork Strategy (CEC 2020b)), underlining the growing interest on life cycle thinking and life cycle approaches from the EU.

In this wide policy context, it is of the utmost relevance to further improve the science-to-policy interface, due to the broad implications of the decisions supported by LCA. The importance of a stricter and more comprehensive implementation of LCA in policies is key to achieve effective benefits in a life cycle perspective and to avoid or limit burden shifting. A number of theoretical options for the implementation of LCA

\footnotetext{
${ }^{1}$ According to the Ecodesign Directive (2005/32/EC), ecological profile means a description "of the inputs and outputs (such as materials, emissions and waste) associated with an energy using product throughout its life cycle which are significant from the point of view of its environmental impact and are expressed in physical quantities that can be measured."
}

into policy already exists, although a consensus on proper technical requirements is missing (Lehmann et al. 2015).

With this regard, it is worth mentioning in particular the role of the European Commission-Joint Research Centre (EC-JRC), which has been working towards providing this policy support through a number of projects and initiatives since 2004. In particular, the European Platform on LCA (EPLCA) (EU, 2020b) constitutes a key tool with this regard, having the objective to promote life cycle thinking in business and in policy making in the EU, as well as providing crucial support for the development of the PEF and the OEF (EU 2020c), in terms of methods and data. Based on the learnings of the EF pilot phase, organised by the EC in the period 2013-2018, the JRC published reports with suggestions for updating the PEF, including the methods for impact assessment. Methodological guidance and updates thereof could be found in the EPLCA (EU 2020c).

This study aims at shedding light on the evolution and the relevance of life cycle thinking and life cycle approaches in policies, illustrating the trend in the use of these concepts and methods in the policy context of EU. This review aims at deepening the understanding on the link between policy and science, shedding light on shortcomings and possible future improvements, in view of supporting the evolution of policies from the adoption of general life cycle-related concepts to more comprehensive uses of LCA, and PEF/OEF methods. This review systematically explores the historical development of the implementation of LCT, LCA, LCC, and environmental footprint and the way they have been integrated in the EU policy context in strategic and legal acts, analysing the period ranging from 1990 to October 2020.

\section{Methods}

A review of EU policy documents was performed in this study as a basis to assess the evolution of occurrence of LCT concepts and LCA-related approaches over time (including also LCC and PEF/OEF). The study focused on the EU due to the wide development of policies mentioning life cycle approaches and methods and considering the presence of a comprehensive online database for the collection of the documents (see Sect. 2.1). To this end, a search customised to a number of different EU policy documents has been conducted. EU treaties are achieved by several types of legal acts that have a different level of prescriptiveness, a different set of requirements and involvement of the Member States (MS) (EU 2020d, e, f, g; EUR-Lex 2020a). This work focused on EU "policies" and on "communications." In this study, documents such as proposals, reports, white papers, and green papers are included under the label "communication". The complete list of definitions of legal acts included under the "policies" and the definition 
of "communications," are reported in the Supplementary Information (SI). Communications were kept separate from the legal acts considering that these documents do not constitute legally binding acts but are rather strategic documents "suggesting" actions or "proposing" legal acts. Standards were not included in the analysis given that the scope of the work was dedicated to legal acts (both legally binding and non-legally binding).

\subsection{Research method}

This review was based on a search performed through EURLex (EUR-Lex 2020b), the online database that provides access to all EU policies (regulations, directives, decisions, etc.) and communications to identify EU policies referring to LCT, LCA, and LCC. Given its more limited development and application in policies, social LCA was not included in this analysis. A number of keywords related to the concepts of LCT and LCA have been screened within title and text of both EU policies and EU communications (e.g. "life cycle thinking," "life cycle assessment"; the details on the search string are reported in the SI), and EU policies or communications presenting these keywords were collected for the period ranging from 1990 to October 2020. Furthermore, other policies and communications identified as potentially relevant (not found through the abovementioned screening but cited in other documents or identified by the authors of this article through their expert judgment) were added to the overall set of legal acts to be investigated.

A refined selection was then performed on collected documents, aiming at excluding documents out of the scope of the present review (e.g. documents dealing with "life cycle" of insects, plants, or other organisms/species; the "life cycle" of projects/programmes, referring to the "life cycle" of people and workers): this refinement was manually performed, critically analysing the context of the legal documents previously gathered.

\subsection{Classification method}

Policies and communications were classified according to the concept and/or method cited in the document, focusing on (i) LCT (life cycle thinking), ${ }^{2}$ (ii) LCA (life cycle assessment), (iii) LCC (life cycle costing), and the European Product and Organisation Environmental Footprint (PEF/ $\mathrm{OEF}$ ). The presence of more than one concept/method was considered (e.g. LCT and LCA, both mentioned): in these

\footnotetext{
${ }^{2}$ For this classification, a "life cycle approach" related to the quantification of environmental "impacts" along the supply-chain was classified as LCT.
}

cases, the document was classified under multiple concepts and/or methods (for instance the new Circular Economy Action Plan (CEC 2020a) was classified under LCT, LCA, and PEF/OEF). The classification was structured according to different perspectives: (i) the relevance of life cycle concepts in policies and communications, (ii) the sectors addressed in policies and communications, (iii) the presence of links to case studies and previous legal acts in communications, and (iv) the specific types of applications of life cycle approaches.

Regarding the relevance of life cycle concepts in policies and communications, in view of understanding the importance and prominence given to LCT, LCA, LCC, and/or $\mathrm{PEF} / \mathrm{OEF}$ in the analysed policies, a further classification was performed:

1. LCT, LCA, LCC, and/or PEF/OEF cited "at the heart" of the document: if the concept/method exhibited a pivotal role and/or was a crucial element for the document itself (e.g. not only mentioned in the preamble, but instead used to set a requirement, an objective for future developments, a selected criterion to be adopted when assessing environmental impacts) or if it was mentioned with a key role in the context of future additional legal acts to be developed;

2. LCT, LCA, LCC, and/or PEF/OEF cited "in the context" of the document: in all the other cases where, for instance, the concept/method was cited in the preamble (e.g. in the recitals) and in other sections in a generic manner, or if the policy was only referring to these concepts as cited into other existing documents.

From the complete list of policies and communications, a specific subset of key documents was selected in view of providing a dedicated and detailed overview of the most relevant policies and communications where LCT, LCA, LCC, and/or PEF/OEF exhibit a crucial role. Furthermore, we performed an analysis of requirements in policies based on a life cycle approach (e.g. requirements related to LCT, LCA, LCC, PEF/OEF). Additional details on the analysis of these requirements are included in tables S4 and S5 of the SI.

Concerning the sectors addressed in policies and communication, all legal acts were classified focusing on their specific sectors of concern (e.g. waste, energy and fuels, construction, etc.). Considering the total number of policies and communication addressed in this review, the most frequently mentioned sectors and field of action (e.g. waste, energy and fuels, construction) were identified and commented. Whenever possible, the same categories were considered for the classification of communications and policies, in order to ease the comparison between these two types of documents (highlighting both similarities and differences). Specific sectors mentioned several times only in policies or only in 
communications were also included. Moreover, general categories (e.g. "others not elsewhere classified (n.e.c.)") were established for policies addressing specific products and specific sectors not represented in multiple documents, or policies related to products in general (e.g. integrated product policies). Similarly, a generic category was also established for communications related to research and other specific programmes (such as funding programmes, e.g. "Horizon $2020 ")$. In the classification procedure, in case of the presence of more than one sector for a single legal document, the latter has been classified in several categories (e.g. a classification within both the "waste" and "energy and fuels" categories). Further details on the abovementioned classifications of policies and communications are reported in the SI. If a single document is relevant for more than one of the selected sectors/identified scope, it is classified accordingly with multiple entries (e.g. the Directive on the promotion of the use of biofuels or other renewable fuels for transport (EC 2003) was classified in the sectors "energy and fuels" and "mobility").

Furthermore, policies were also investigated in view of identifying any relevant case in which LCA, LCC, and/or $\mathrm{PEF} / \mathrm{OEF}$ were directly applied in the policies or indicated as the reference method for conducting an assessment. On the other hand, communications were further analysed to investigate the links with existing or foreseen legal acts. In case of recent proposals, not always the proposed policy has already been set up. In some of these cases, the proposals were identified as "possibly relevant in future," whenever the proposed policy was identifiable as possibly relevant with regard to future development/implications of the LCT concept or of the LCA, LCC, PEF/OEF methods.

The communications were also categorised in view of providing insights on the specific type of application of the life cycle approach, to whether they were referring

1. to LCA, LCC, and/or PEF/OEF results: when results from life cycle analysis (i.e.: LCA, LCC, PEF/OEF) are mentioned in the analysed document or are cited from other studies;

2. to LCT, LCA, LCC, and/or PEF/OEF as implemented in other legal acts, currently or in the past: when the role of life cycle thinking and life cycle approaches are mentioned as being pivotal in other legal acts or when other legal acts -where these concepts are relevant- are cited;

3. to LCT, LCA, LCC, and/or PEF/OEF as important to be implemented, in the future: when it is explicitly mentioned that life cycle thinking and life cycle approaches are crucial elements to be considered and implemented in the future.
A parallel classification was conducted by excluding specific subsequent legal acts (as well as other linked documents, such as working plans or amendments) derived from the implementations of the Ecodesign Directive (EC 2009a) and the Ecolabel Regulation (EC 2010a). ${ }^{3}$ The scope of this analysis was to unveil individual initiatives removing those that were implementations of existing ones. The results of this analysis are presented in the SI.

\section{Results}

The following sections illustrate the results of this study, following the methodological approach presented in Sects. 2.1 and 2.2.

\subsection{Results of the search}

According to the method described in Sect. 2.1, overall, a total of 243 policies and a total of 348 communications were gathered through the EUR-Lex search, the screening of the citations inside each reviewed document, as well as those identified via expert judgment. After this first step, documents not relevant for the present review were discarded, resulting in a total of 159 policies and a total of $167 \mathrm{com}$ munications that were further analysed and classified as presented in the following sections.

\subsection{Results of the classification}

In order to better understand the importance given to the life cycle related approaches cited in the selected documents, a distinction between the life cycle concepts/methods cited "at the heart" or "in the context" of the legal acts classified was implemented (see Sect. 2.2).

Overall, LCT/LCC/LCA and/or PEF/OEF were found to be "at the heart" in $60 \%$ of the policies classified and in $45 \%$ of the communications classified (see Sect. 2.2). Table 1 presents an overview of the most relevant policies and communications where LCT, LCA, LCC, and/or PEF/ OEF are crucial, starting from the year 2000. A detailed description of the policies and communications included in Table 1 is presented in the SI, whilst additional comments are reported in the Discussion section.

\footnotetext{
3 About 24 Implementing measures and 57 decisions have been published subsequent to the Ecodesign Directive (EC 2009a) and the Ecolabel Regulation (EC 2010a) respectively, to define requirements and criteria for the application to specific product groups.
} 
Table 1 Overview of the most relevant policies and communications classified, starting from the year 2000

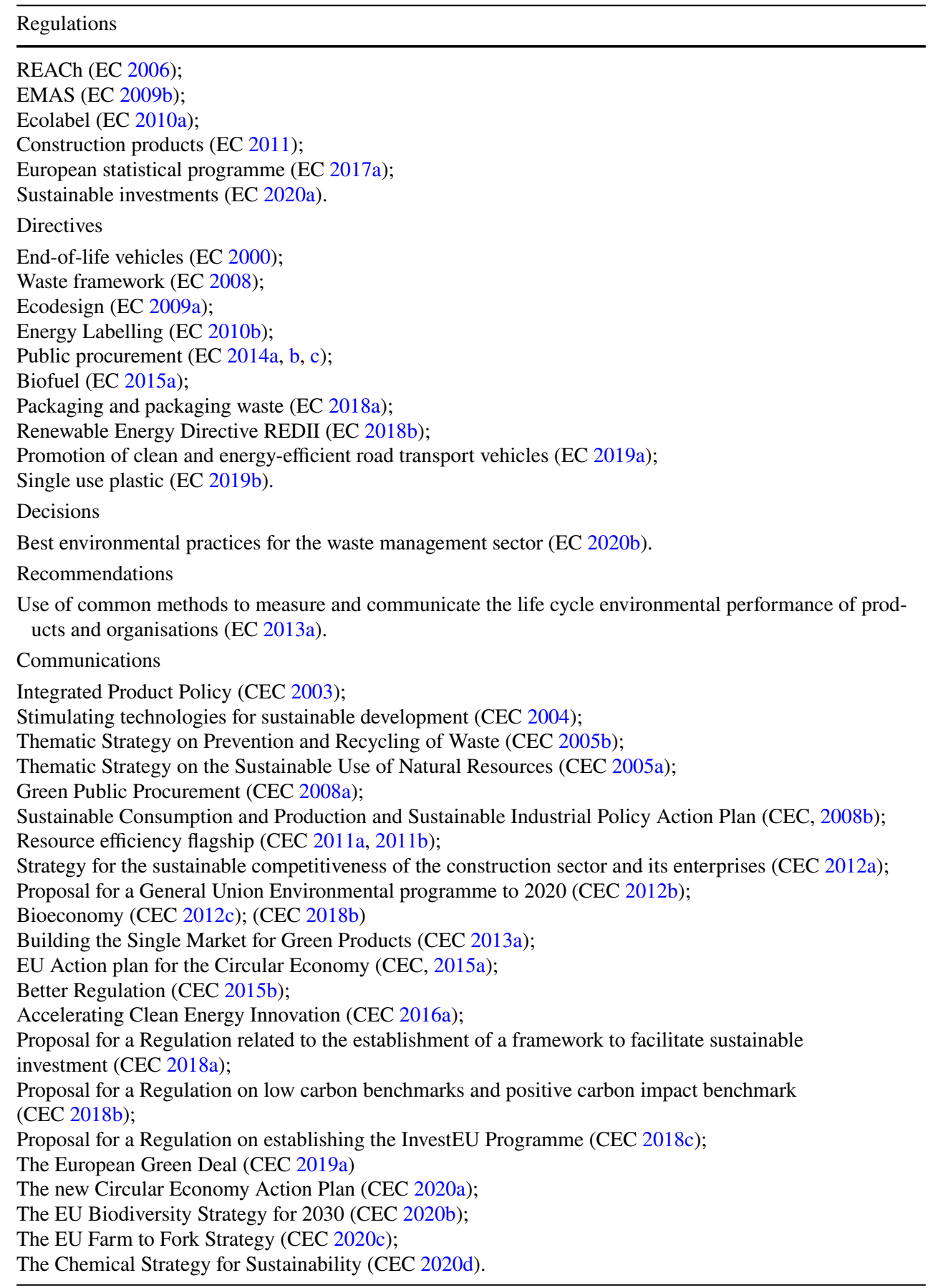

In particular, additional details on the contents of the most relevant classified policies and communication listed in Table 1 are reported in the Table S4 in the SI. In Table S4 each relevant policy and communication is listed from the oldest to the newest. Information regarding the linked policies/communications (and amendments, etc., if any) together with the assessed life cycle concepts/approach are specified. A brief description of the policy/communication itself is also reported.
Figure 1 illustrates a breakdown for each type of policy and communication as previously classified. Communications constitute the main type of analysed documents, followed by decisions and regulations, which are the most represented among the classified policies. Most of the classified decisions are linked to the Ecolabel Regulation (EC 2010a), whilst most of the classified regulations are linked to the implementation of the Ecodesign Directive (EC 2009a). Therefore, a parallel analysis was performed by analysing 


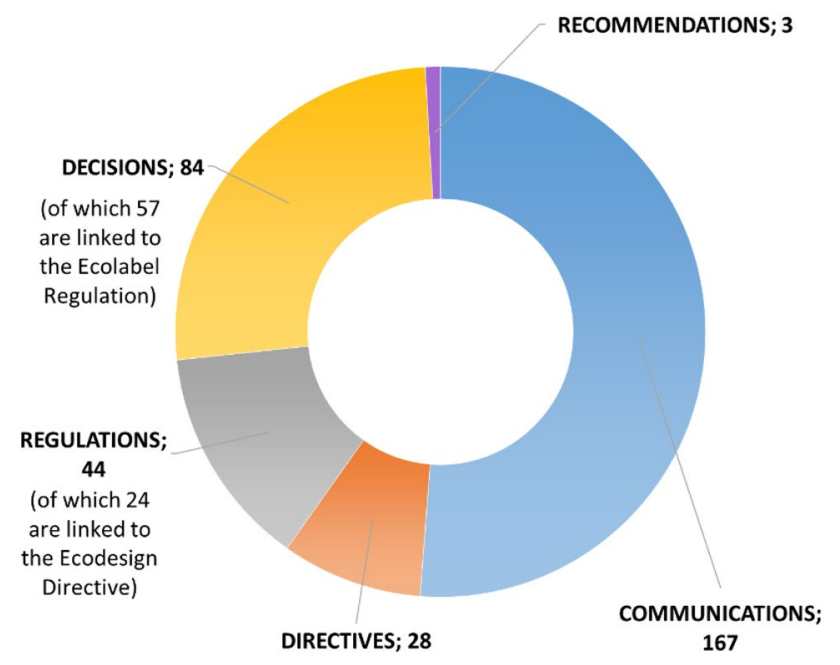

Fig. 1 Relative distribution of classified regulations, directives, decisions, recommendations, and communications. Numerical results indicate the number of individual policy documents

the results of the classification when removing these legal acts from the overall picture (the results of this analysis are presented in the SI). Decisions and regulations cover the majority of the policies classified, followed by directives (in line with general EU legal acts statistics, EUR-Lex 2020c), while Recommendations represent only a very minor share.

Figure 2 highlights the results of the classification of sectors of intervention of the identified policies. The specific description of the sectorial categories considered in Figs. 2 and 3 is reported in the SI.

Household goods (e.g. hygiene products) and appliances (e.g. vacuum cleaners, lamps) manifest an evident dominating role, mainly as specific implementations of the Ecolabel
Regulation (in case of Decisions) and the Ecodesign Directive (in case of regulations). However, it is worth noticing that the dominance of this category was also due to its intrinsic heterogeneity, since it covers a wide array of different products. Moreover, the "research and other programmes" sector is particularly relevant (e.g. funding programmes such as "LIFE" and "Horizon2020" and other specific EU programmes, such as the European statistical programme), followed by "energy and fuels" and waste.

Figure 3 reports the results of the classification for the sectors as conducted on the EU communications. In fact, communications show a coverage of a wide array of different sectors and topics, for which it was not always possible to identify a specific category. However, when a single sector category was identifiable, a predominance of communications dedicated to "energy and fuels" and "circular economy and sustainable development" is evident. Although communication has a broader scope than the classified policies, energy was found to be a key and transversally relevant sector in both policies and communications (Figs. 2 and 3).

Figure 4 provides an overview of the evolution of the implementation of LCT, LCA, LCC, and PEF/OEF over time, by presenting the year in which the identified policies and communications have been published. On the other hand, Fig. 5 reports the evolution of LCT/LCA/LCC and PEF/OEF in the EU policies by type of policy. In both Figs. 4 and 5, synthetic names of some of the most relevant policies/communications per year are reported. An overall growing trend of LCT/LCA/LCC and PEF/OEF-based policies in recent years was noticeable from Figs. 4 and 5.

Only in a few cases, LCA, LCC, and/or PEF/OEF have been directly applied in the policies or indicated as the reference method for conducting an assessment. Decisions

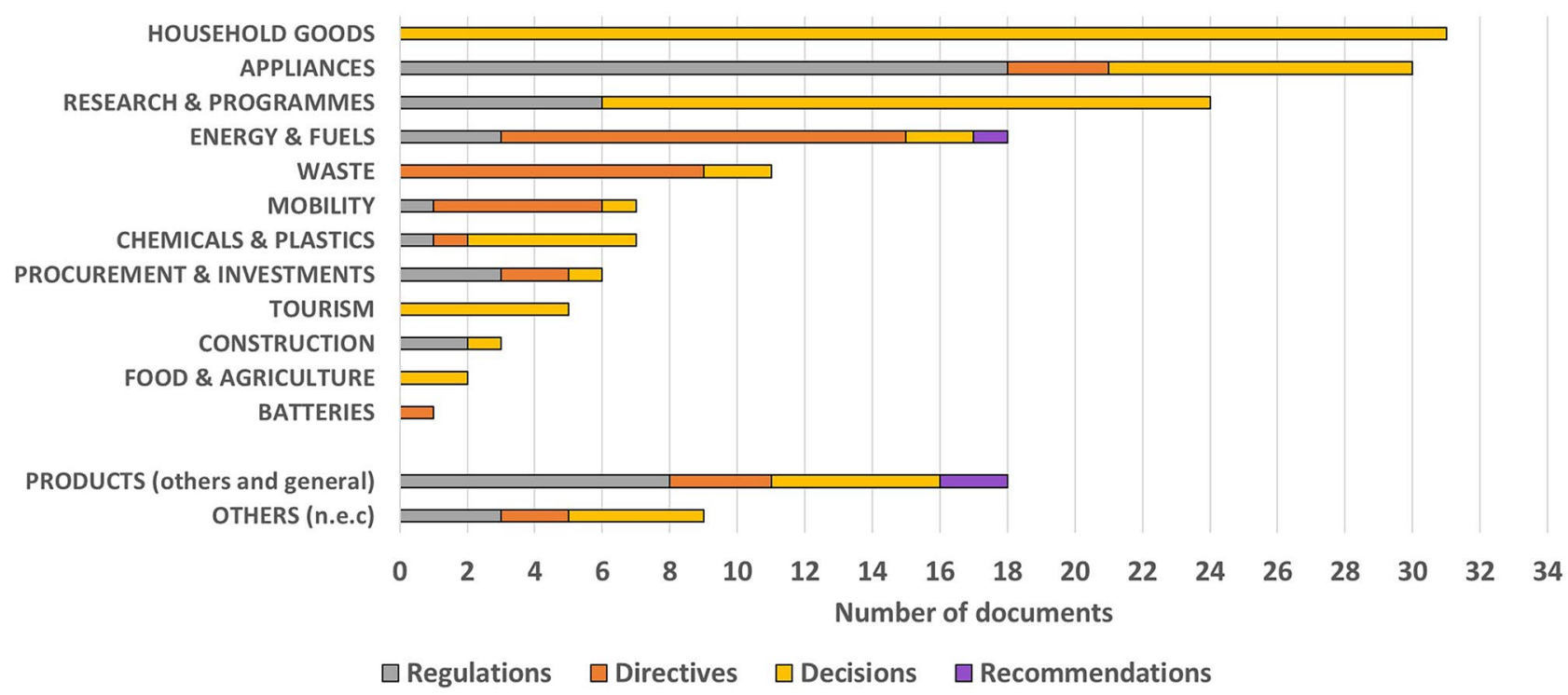

Fig. 2 Relative distribution of sectors addressed in the 159 classified policies (n.e.c. $=$ not elsewhere classified) 


\section{Sectors of communications}

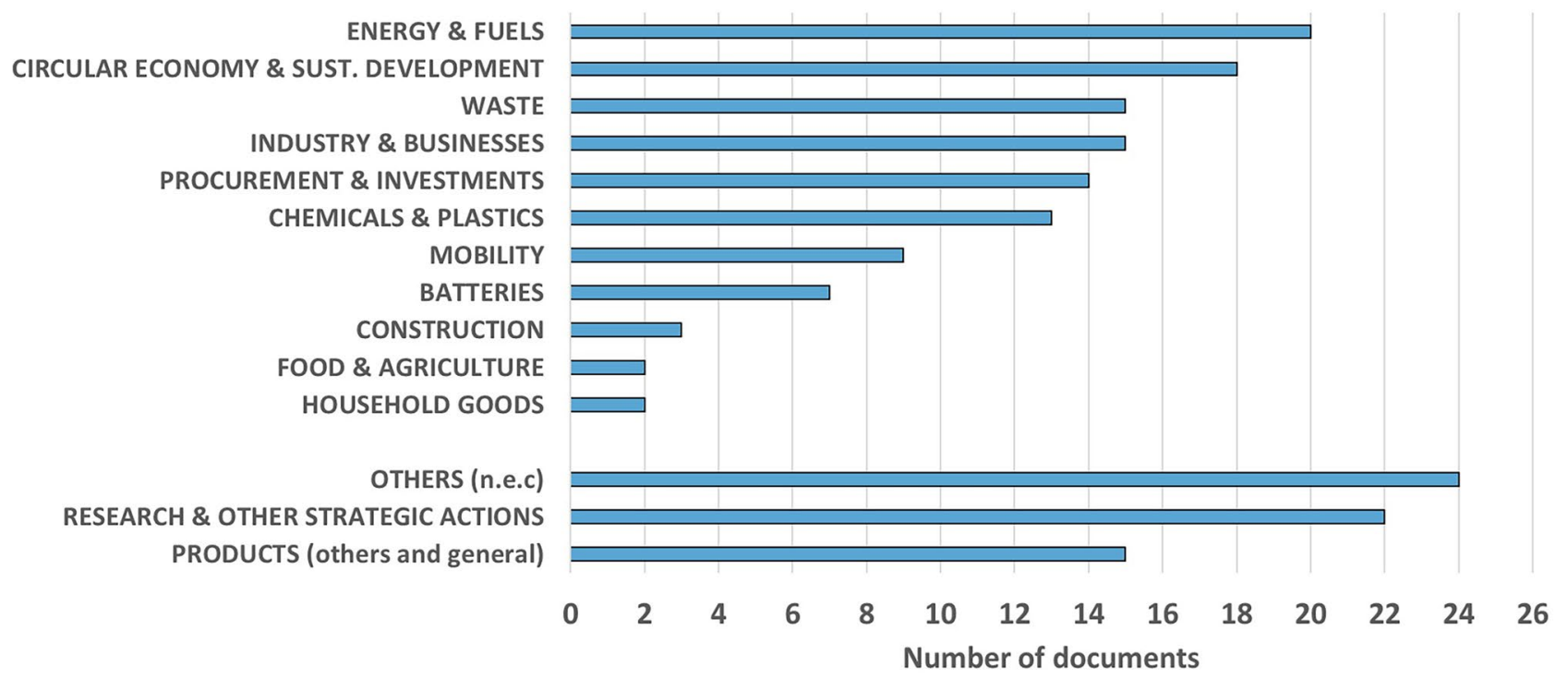

$\square$ Communications

Fig. 3 Relative distribution of sectors addressed in the 167 classified communications (n.e.c. $=$ not elsewhere classified)

dealing with Best Environmental Management Practices (BEMP) (e.g. decisions related to EMAS, EC 2019c, 2019d) recognised the key role of LCA methodology.
The key role of LCA has been further acknowledged in the development of the PEF/OEF methods, which have been notably defined in the 2013 EU Recommendation

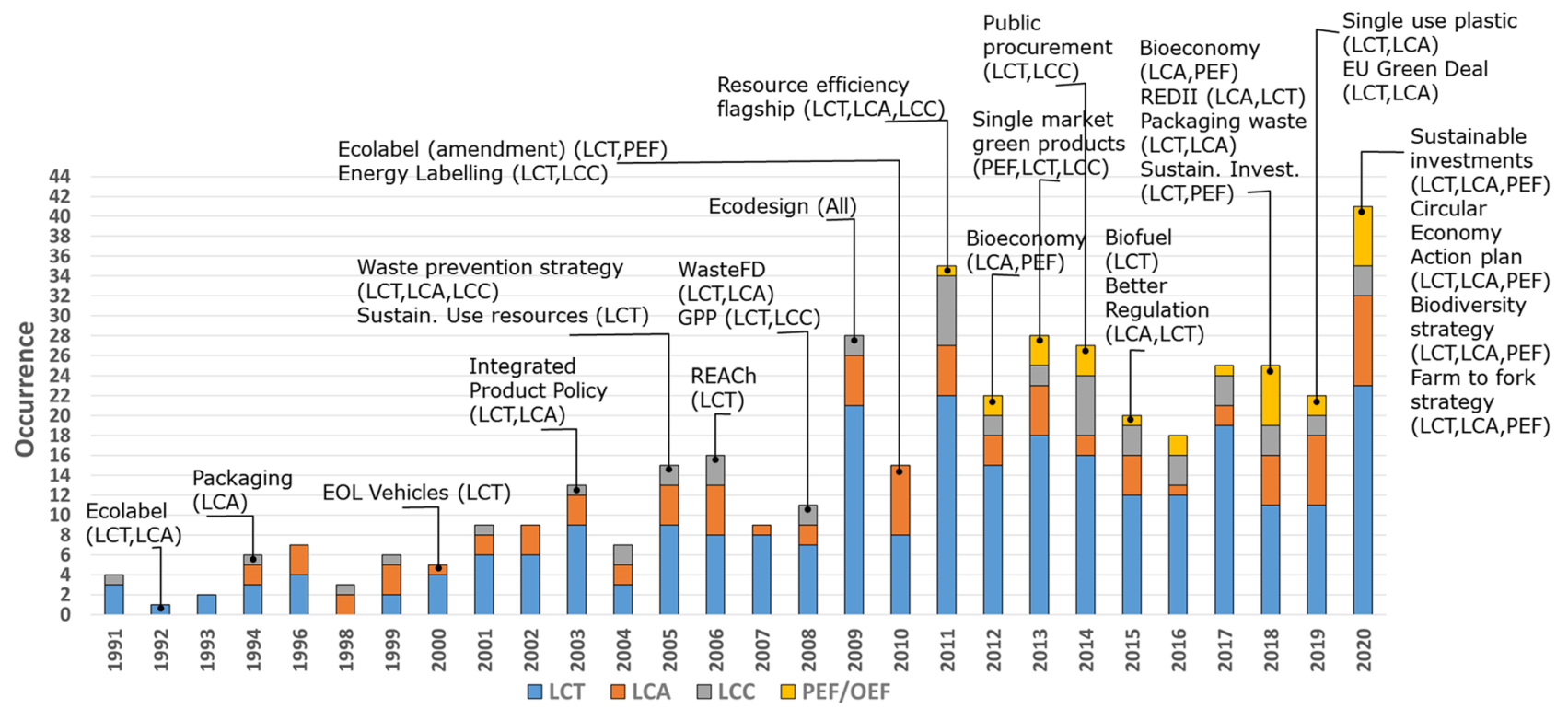

Fig. 4 Evolution of the implementation of LCT, LCA, LCC, and $\mathrm{PEF} / \mathrm{OEF}$ in policies and communications (note: when relevant, more than one concept or method is reported per policy. No documents were found for the years 1995 and 1997). The documents explicitly mentioned in the figure represent examples of the most relevant policies/communications developed over time. Additional information on the reported policies and communications: 1992: (EC 1992);
1994: (EC 1994); 2000: (EC 2000); 2003: (CEC 2003); 2005: (CEC 2005a, b); 2006: (EC 2006); 2008: (EC 2008; CEC 2008a); 2009: (EC 2009a); 2010: (EC 2010a, b); 2011: (CEC 2011b); 2012: (CEC 2012c); 2013: (CEC 2013a); 2014: (EC 2014a, b, c); 2015: (EC 2015a; CEC 2015b); 2018: (CEC 2018d; EC 2018a, b; CEC 2018a); 2019: (EC 2019b; CEC 2019a); 2020: (EC 2020a; CEC 2020a, b, c). For further details, see the SI 


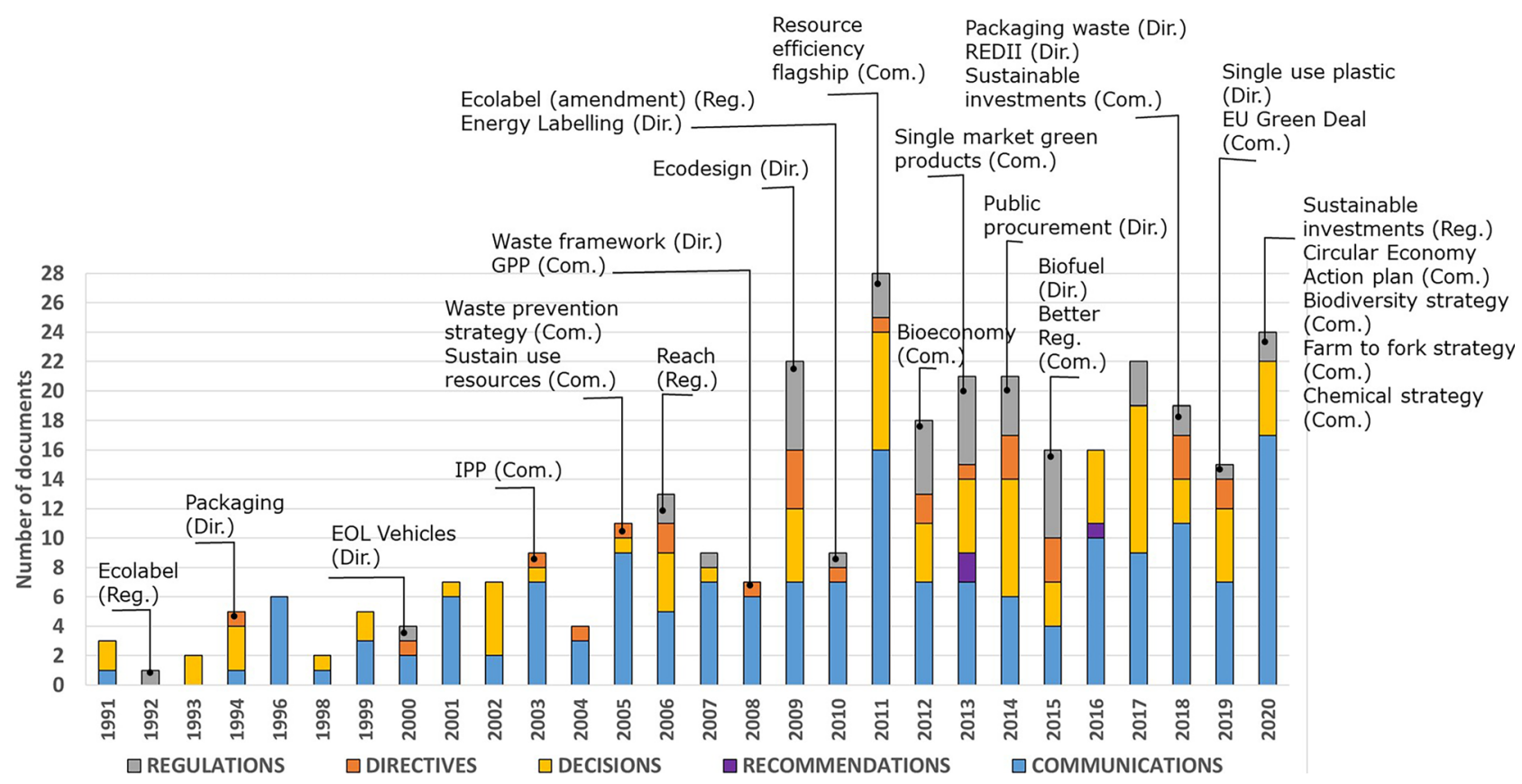

Fig. 5 Evolution of the implementation of LCT, LCA, LCC, and PEF/ OEF in policies and communications by policy type (no documents were found for the years 1995 and 1997). The documents explicitly mentioned in the figure represent examples of the most relevant policies/communications developed over time. Additional information on the reported policies and communications: 1992: (EC 1992); 1994: (EC 1994); 2000: (EC 2000); 2003: (CEC 2003); 2005: (CEC 2005a, b); 2006: (EC 2006);

(EC 2013a) and which increasingly represent the reference LCA methods for the EU policies. LCC was instead considered as the reference method in policies dealing with public procurement (e.g. directives: EC 2014b, 2014c) and for the definition of Ecodesign requirements (e.g. the 2009 Directive EC, 2009a, for energy-related products). However, LCC was not described in detail in these legal acts: life cycle costs were mentioned as a relevant aspect to be monitored and minimised, whilst specific details on the advantages and disadvantages and information on the implementation of a life cycle costing method were neglected.

Only 27 out of 167 classified communications referred to LCA, LCC, and/or PEF/OEF results. Existing LCA studies were cited as general examples (e.g. CEC 2008a) regarding the cost effectiveness of green public procurement in sectors where green products are not more expensive than nongreen alternatives. The communication (CEC, 2014) cited sectorial studies on the environmental benefits of recycling (e.g. gypsum board production), especially with regard to the achievable reductions of the global warming potential. In addition, LCA, LCC, and/or PEF/OEF results were also mentioned in the context of greenhouses gas emission savings (e.g. communications: CEC 2010a, 2010b).
2008: (EC 2008; CEC 2008a); 2009: (EC 2009a); 2010: (EC 2010a, b); 2011: (CEC 2011b); 2012: (CEC 2012c); 2013: (CEC 2013a); 2014: (EC 2014a, b, c); 2015: (EC 2015a; CEC 2015b); 2018: (CEC 2018d; EC 2018a, b; CEC 2018a); 2019: (EC 2019b; CEC 2019a); 2020: (EC 2020a; CEC 2020a, b, c). For further details, see the SI

Furthermore, 54 communications cited other relevant legal acts referring to LCT, LCA, LCC, and/or PEF/OEF. Among the most cited acts, it is possible to highlight the 2008 Waste Framework Directive (EC 2008), the 2009 Ecodesign Directive (EC 2009a), the 2010 Ecolabel Regulation (EC 2010a), the 2011 regulation on construction product (EC 2011), and the 2015 Biofuel directive (EC 2015a).

In 80 communications it was identified a specific reference to the relevance of implementing a life cycle approach. A number of communications (namely CEC 2013a, 2015a, 2018d, 2018b) cited the PEF/OEF methods, and in particular, the 2013 communication (CEC 2013a) on building the Single Market for Green Products which set the framework for the PEF/OEF methods to calculate robust and comparable information on the environmental performance of products and organisations.

A dedicated analysis was additionally performed (Table S5, S1) to assess the level of implementation of life cycle-based requirements in policies. A total of 29 legal acts were analysed in detail. It resulted that, in general, strict requirements for life cycle methods are missing. Even when LCA or LCC are required or strongly suggested, precise guidelines for their implementation are not commonly provided. For instance, in the case of financial rules 
applicable to the general budget of the EU (contracts awarding; EC 2015b, c), a list of elements to be covered by a LCC study were indicated, but specific methodological requirements on how to perform the study were not provided. Furthermore, the directive (EC 2019b) defined measures to reduce life cycle environmental impacts of single-use plastics, although no further detailed information was reported on how to perform these assessments.

On the other hand, a strong preponderance of LCA and LCC in policies related to environmental practises was noticeable, with a number of legal document (e.g. EC 2017b, 2018c, 2019e) that prescribed using LCA/LCC studies as benchmarks of excellence. In some cases (e.g. EC 2019f), the ISO standards (ISO 2006a, b) were mentioned as the reference guidelines according to which a LCA study should be performed. Lastly, PEF/OEF were extensively described in EC (2013a), illustrating in the annexes the complete methodology for performing PEF/OEF-compliant studies. The EC (2013a) was also one of the few cases in which a comprehensive LCA-based method was fully described in a legal document.

Among the 167 classified communications, 25 were proposals (for a regulation, for a directive, for a decision) resulting in other legal acts already finalised and published. ${ }^{4}$ On the other hand, other proposals related to policies envisioned in the future but not already operating were analysed. In the latter case, it is worth mentioning the 2020 communication (CEC 2020e), that demanded the active engagement of stakeholders at all levels of governance, to ensure that EU climate and environment laws are effectively implemented. This communication forms the EU's basis for achieving the United Nation's 2030 Agenda and its Sustainable Development Goals (UN 2015). Lastly, 2 communications, also explicitly referred to life cycle-related potential trade-offs. Notably, in the 2011 flagship initiative for a resource-efficient Europe (CEC 2011a), it was mentioned that in order to make the right choices with regard to resource-efficiency policies, there is the need to consider the whole life cycle of the way resources are used, including along the value chain, and the trade-offs between different priorities. Moreover, in the 2005 Thematic Strategy on the prevention and recycling of waste (CEC 2005b), it was stated that all phases in the life cycle of a resource need to be considered as there can be trade-offs between different phases, and measures adopted to reduce environmental impact in one phase can increase the impact in another. Despite being a crucial aspect to be considered and understood when interpreting life cycle-based

\footnotetext{
${ }^{4}$ For instance, the 2016 proposal (CEC 2016c) on the financial rules applicable to the general budget of the Union and the related regulation in 2018 (EC 2018d); the 2005 proposal (CEC 2005c) on waste and the related directive in 2008 (EC 2008).
}

comparative results (Prado-Lopez et al. 2016), the results of our analysis on EU communications show that trade-offs are generally implicitly taken into consideration when referring to life cycle approaches.

\section{Discussion}

Although the classification and interpretation of the results were affected by a certain level of subjectivity, the collected information are nonetheless useful for providing qualitative insights on the embodiment of life cycle thinking and life cycle approaches in EU policies and communications. Moreover, these results could be used to provide recommendations for future improvements.

The EU has already made significant steps forwards in the implementation of life cycle in policies, through various documents starting with the Integrated Product Policy (IPP) (CEC 2001, 2003), as it is possible to notice from Table 1 and the $\mathrm{S} 1$.

In the abovementioned IPP, the EC concluded that LCA provides the best framework for assessing the potential environmental impacts of products that is currently available. However, the need for more consistent data and consensus on LCA methodologies was underlined.

Later, LCT and LCA were then further integrated in specific sectorial policies, as the Thematic Strategy on the Prevention and Recycling of Waste (CEC 2005b), the Thematic Strategy on the Sustainable Use of Natural Resources (CEC 2005a), the Sustainable Consumption and Production, and Sustainable Industrial Policy Action Plan of 2008 (CEC 2008b). In 2005, the IPP communication was particularly strengthened by the Thematic Strategy on the Sustainable Use of Natural Resources of the EC (CEC 2005a), which focuses on decoupling economic growth from environmental impacts. LCT is core to this thematic strategy, being a foundation of the indicators that will be developed to monitor progress across the community.

In the first decade of the 2000s, LCT was mentioned as a key approach in the Sustainable Consumption and Production and Sustainable Industrial Policy (SCP/SIP) Action Plan (CEC 2008b), as well as more overarching policy documents, such as the Resource Efficiency Flagship Initiative of the Europe 2020 Strategy (CEC 2011a), and related Roadmap (CEC 2011b). Of particular note here is the stated objective of the Roadmap to a Resource Efficient Europe according to which, by 2050, the EU economy shall have developed in way able to accommodate resource constraints and planetary boundaries.

In 2013, together with the Recommendation establishing the PEF/OEF methods (EC 2013a), a landmark communication was released: the Single Market for Green Products communication (CEC 2013a). Among all others, 


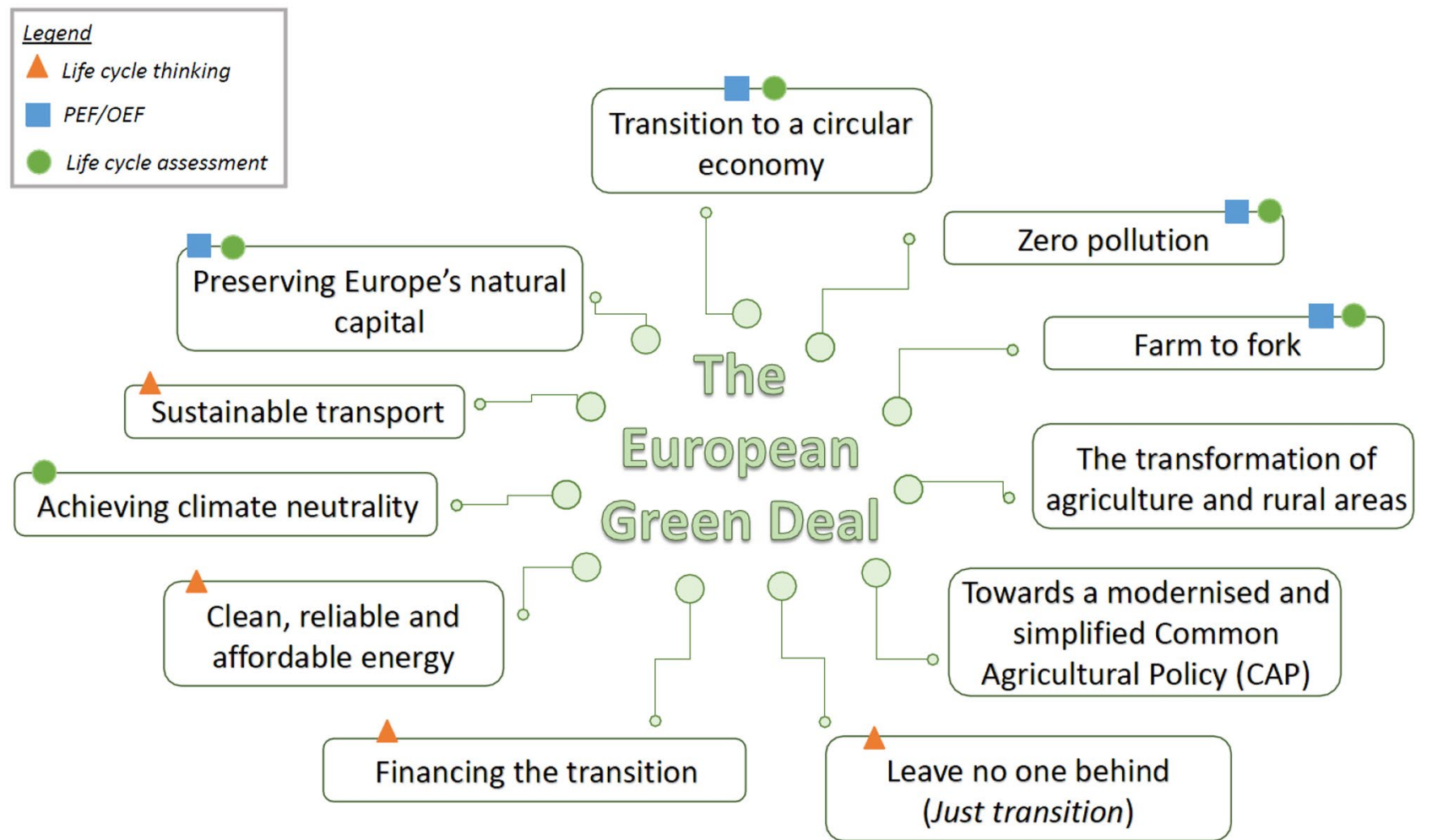

Fig. 6 An overview of the role of LCT, LCA, and PEF/OEF within the EU Green Deal and related policies initiatives

the PEF/OEF methods constitute one of the most relevant game changers in the field of LCA. In fact, these are the first systematic attempts to have a robust and comparable method for LCA applied in policies and green claims, even from a legal point of view. The PEF and OEF methodologies build on existing LCA-based methods aiming at harmonising them and at establishing a tool to assess the environmental performance of products, services and companies based on a comprehensive assessment of environmental impacts over the life cycle. The 2013 EC Recommendation promoted the PEF/OEF in view of measuring and communicating the life cycle environmental performance of products or organisations. The final goal was to reduce and overcome the fragmentation of available methods for measuring environmental performances.

In view of enabling comparability of products and organisations performances, the Product Environmental Footprint Category Rules (PEFCRs) and Organisation Environmental Footprint Sector Rules (OEFSRs) were developed by a Technical Secretariat, composed of at least $51 \%$ of the EU market, plus other stakeholders. Currently, 19 PEFCRs (covering for instance food, batteries, laundry detergents, metal sheets, laundry detergents, etc.) and 2 OEFSRs (related to copper production and retail) are available (EU 2020h). The development of a PEFCR/OEFSR is a crucial aspect for improving the robustness of the $\mathrm{PEF} / \mathrm{OEF}$, since these rules are established on the basis of an agreement between the scientific community and the industry. However, even if more PEFCRs are expected to be developed in the next years, the establishment of a PEFCR is a challenging process. The development process is commonly time-consuming and the final agreement between the involved parties on a specific PEFCR is not ensured, therefore limiting the potential prompt implementation in policies.

In the most recent years (from 2016 onwards, with particular emphasis in the years 2018, 2019, and 2020), the number of policies and communications that are explicitly citing concepts and methods related with life cycle is growing. It is definitely worth of mention the 2019 communication (CEC 2019a) on the European Green Deal. This communication set the commitment of the EC to tackling climate and environmental-related challenges, aiming to transform the EU into a fair and prosperous society with a modern and resource-efficient economy and setting the target for the carbon neutrality of the EU by 2050. A number of other communications are also going in the same direction, complementary to the Green Deal by tackling some specific topics, as illustrated in Fig. 6.

For instance, in case of the food sector (CEC 2020c), the relevance of a life cycle viewpoint was outlined, since a better information from "farm to fork" is foreseen (covering where the food comes, its nutritional value, and its 
environmental footprint). Chemicals (CEC 2020d) were furthermore considered, with the aim of ensuring sustainability by minimising their environmental footprint. In the case of industry (CEC 2020f), a reduction of their carbon footprint ensuring sustainability was also envisaged. Moreover, circular economy was mentioned in view of proposing sustainable solutions to reduce EU consumption footprint, as it is detailed in the related communication (CEC 2020a). The measures proposed by the EU Green Deal will significantly benefit EU companies, in particular by means of and improved digitalisation and information flow, providing more detailed information on product's origin, composition, repair and end-of-life handling, therefore enabling a more circular economy. This will improve the reliability of companies' "green claims," therefore reducing the risk of "greenwashing" and the proliferation of unreliable and not scientifically based environmental labels that are leveraging on the worldwide growing interest on sustainable topic. Lastly, many other fields of action (e.g. product policies, investments, biodiversity) were addressed as well in the European Green Deal, identifying this communication as a key document for the future of Europe. The analysis of the abovementioned documents indicated that no case study or benchmarks are mentioned and that they do not include any specific detail on how to perform a LCA. However, despite not proposing specific requirements, a stronger commitment to the implementation of LCA-related results is evident.

From Table 1, the main key sectors of the classified policies and communications can be identified. In particular, both the waste sector (e.g. communication: CEC 2005b; directives: EC 2008, 2018a) and the construction sector (e.g. regulation: EC 2011; communication: CEC 2012a) can be highlighted, since in these cases, life cycle approaches and methods, in particular LCA and LCC, exhibit particular relevance. Most of the abovementioned policies and communications focused mainly on LCA, whilst LCC was especially mentioned in specific context, such as the directives on procurement (EC 2014a, b, c) or on specific sectors, e.g. the construction sector. For instance, in the 2012 strategy for the sustainable competitiveness of the construction sector and its enterprises (CEC 2012a), LCC was mentioned as a methodology for supporting the development of a model for Green Public Procurement and for sustainable development principles related to regional policies.

In two other fields, Green Public Procurement and Sustainable Public Procurement (communication: CEC 2008a; directives: EC 2014a, b, c), life cycle concepts have pivotal roles in the procurement processes themselves. Moreover, in the 2017 proposal for a regulation on low carbon benchmarks and positive carbon impact benchmarks (CEC 2018b), that resulted in the 2019 regulation (EC 2019g), the PEF/ OEF methods were remarkably envisioned as "the preferred option" among the future policy alternatives for harmonising the methodology to be applied to low-carbon indices and "positive carbon impact" indices to help investors compare the carbon footprint of investments.

In addition, other relevant sectors in the field of life cycle were identified. This is particularly the case of energyrelated policies: the 2005 Directive (EC, 2005) on Ecodesign requirements for energy-using products, the 2016 communication (CEC 2016a) on accelerating clean energy innovation, the 2017 regulation (EC 2017c) on energy labelling, the 2018 RED II Directive (EC 2018b) on renewable energy, and the 2019 Directive (EC, 2019a) on the promotion of clean and energy-efficient road transport vehicles and communications specific to batteries (e.g. communications: CEC 2018e, 2019b). The analysis of life cycle concepts and approaches in the policy and communication documents for the energy category highlights how the main focus is related to the transition towards the use of the renewable energies and fuels. The directive of 1998 relating to the quality of petrol and diesel fuels (EC 1998) has been updated and mentioned in recent years (EC 2009c, 2015a, d), especially in the field of the monitoring and the reduction of life cycle greenhouse gases emissions and the improvement of the quality of petrol and diesel fuels towards the promotion of the use of renewable energy sources. With this regard, the promotion of biofuels and other renewable fuels was proposed already in 2003 (EC 2003) introducing minimum proportion of biofuels and other renewable fuels placed on the Member States markets. Moreover, transversal issues related to the adoption of biofuels were mentioned, such as the indirect land-use change related to biofuels and bioliquids as indicated in the report of 2010 (CEC 2010a). Lastly, recent document stemming from the European Green Deal (CEC 2019a) focused on alternative energy sources, such as hydrogen (CEC 2020g), which is considered a key energy carrier for the reduction of life cycle greenhouse gas emissions by minimum $50 \%$ and towards $55 \%$ by 2030 , in a cost effective way.

Furthermore, two policies have been also relevant concerning green purchasing: (i) the 2016 communication (CEC 2016b) that resulted in the 2018 regulation (EC 2018e) on the Governance of the General Union, which cites that MS shall require a life cycle thinking approach to energy suppliers in order to reduce life cycle greenhouse emissions, and (ii) the 2017 communication (CEC 2017a) related to the EU Environmental Implementation Review, where a LCT perspective was presented as a successful example of an approach (that has been adopted by many MS) able to make purchased goods and services more sustainable through public procurement.

Whilst Table 1 provides insights on the main key legal acts analysed, Fig. 1 illustrates that decisions and regulations were essential legal acts with regard to the entirety of the classified policies (a total of 159). Decisions frequently were related to the "research and other programmes" sector 
(for instance related to the adoption of the multiannual LIFE work programme or the establishment of the specific programme implementing "Horizon 2020") and were also commonly present with regard to the household goods sector (given the numerous specific applications of the Ecolabel Regulation) (Fig. 2). Regulations on the other hand are the most binding EU policies acts (see the SI): LCT/LCA/LCC have been crucial into regulating appliances (in particular the numerous specific applications of the Ecodesign Directive) as well as in the "research and other programmes" sector (for instance establishing the "Horizon2020" programme programmes or concerning LIFE + programme) (Fig. 2).

With regard to directives, LCT/LCA/LCC have been crucial for the waste sector (e.g. waste, packaging and packaging waste, Waste Electrical and Electronic Equipment-WEEE) and for the "energy and fuels" sector (e.g. petrol and diesel fuels, biofuels, and other renewable fuels for transport). However, compared to regulations, the classification of EU directives showed wider application of LCA to different sectors (e.g. waste, mobility, energy, and fuels) (Fig. 2). It is however important to keep into consideration that beside their frequency, the content of the classified legal acts was relevant as well. For instance, results indicate that Recommendations were less represented compared to other legal acts. However, for instance the Recommendation of 2013 (EC 2013a) introduced the PEF/OEF methods, which had an outstanding relevance in the following LCA-related policies and communications, especially in the more recent years.

Most of the classified communications (Fig. 3) have been mainly implemented with regard to (i) "energy and fuels" (e.g. focusing on clean energy innovation and a rational use of energy, and fuels such as biofuels and hydrogen) and (ii) "circular economy and sustainable development," mainly in recent years (due to the increasing focus on these topics, noticeable for instance in the European Green Deal in 2019, in the Circular Economy Action Plan and in the Chemicals Strategy for Sustainability in 2020, etc.). The idea of circular economy has roots in concepts of real-world systems and cycles, where waste of resources is minimised and materials are maintained for as long as possible "in circle," therefore reducing waste generation. In recent years, the EU has promoted the transition towards a circular economy, to achieve a regenerative growth model able to maintain production and consumption systems within sustainable levels. Most of the policies and communications discussing the concepts of Circular Economy were published in the years from 2019 to 2020, leveraging on two key earlier documents: the EU action plan for circular economy of 2015 (CEC 2015a) and the communication on the role of waste-to-energy in the circular economy of 2017 (CEC 2017b). Furthermore, waste (e.g. end-of-life vehicle, waste management) and "industry and business" (with a preponderance of documents related to public procurement) are two other relevant sectors among the analysed communications, together with "research and other specific programmes," that are assessing a wide array of topics (e.g. nanotechnology, the urban environment, economy in the EU Atlantic area).

In general, results highlight that life cycle concepts (especially LCT) have been primarily developed and implemented in product policies, showing a clear higher level of maturity in the implementation in this field compared to others.

Lastly, from Figs. 4 and 5, it was evident the presence of early legal acts including life cycle considerations. In fact, the first ISO standards formalising the LCA methodology are dated 1997-1998 (ISO 1997), which were then substituted by the more recent standards (ISO 2006a, b). Results indicate the presence of policies and communications which already contained LCT concepts before 1997. Notably, a LCT approach was already mentioned in 1991 in the decision related to research and technological development in the field of industrial and materials technologies (EC 1991), in which considerations on the whole products life cycle were seen as crucial for a revitalisation of EU manufacturing processes. In the regulation of 1992 (EC 1992), the eco-label award scheme was established for the first time. This regulation focuses on the design, production, marketing, and use of products which have a reduced environmental impact during their entire life cycle. This regulation was anticipated by the related proposal in 1991 (CEC 1991). Furthermore, in 1994 the directive (EC 1994) on packaging and packaging waste was published, in which it was stated how the Commission shall promote the preparation of EU standards relating to criteria and methodologies for life cycle analysis of packaging. It is also worth noticing how the environmental footprint was already mentioned even when the method was not precisely defined yet (i.e.: before the 2013 recommendation, EC, 2013a). In fact, some earlier communications (CEC, 2012d, e, 2013b) highlighted how the Commission intended to recommend the environmental footprint as best practices and methodologies in the field of life cycle assessment.

Furthermore, the application of LCA for macro-scale analysis has increasingly gained interest in the policy context. EC-JRC has developed a set of life cycle based indicators for assessing the environmental impact of consumption in Europe (Consumption and Consumer footprint, Sala et al. 2019). An example of the use of these indicators, is in the Circular Economy Action Pan (CEC 2020a) which mentions consumption footprint in the section on monitoring. However, also other policies refer to the need of reducing the overall footprint, i.e. in the case of the "farm to fork" communication (CEC 2020c), aiming at the reduction of the overall footprint of the food system.

Even if LCA, LCC, and especially PEF/OEF are increasingly relevant, LCT is continuosly mentioned in policies, in more and more sectors of intervention. It is nonetheless worth mentioning that LCT exhibits an overall slight 
reduction in its yearly frequency when the 57 decisions related to Ecolabel criteria for specific products and the 24 regulations related to specific Ecodesign implementations are removed (see the SI). This aspect constitutes a particularly relevant element of reflection: in fact, in many cases, "life cycle" was addressed and cited only as a general and rather unspecified concept, while more stringent and rigorous methods (such as LCA and PEF/OEF) were commonly cited in view of future development or within few key regulations and/or directives (e.g. the EMAS regulation (EC 2009b), the renewable energy Directive (EC, 2018b), the "single use plastic" Directive (EC 2019b), the sustainable investments regulation (EC 2020a)).

A number of key aspects can be identified to ensure applicability of LCA into policies. When life cycle assessment is applied to specific requirements (i.e. those set into products' policies), it is crucial to grant transparency, reproducibility and verifiability of the results. Based also on similar experiences on the inclusion of environmental requirements into policies (e.g. those related to raw materials sourcing, durability, end-of-life management (Ardente and Mathieux 2014)), a system for the verification of LCA results is probably the most relevant challenge to overcome. In fact, an important aspect worth considering is that in view of ensuring clear (mandatory) LC-based requirement in policies, these requirements should be both more binding but also verifiable. The method for the verification of LCA results in policy requirements (necessary, for example, to prove the achievement of a certain target) needs to be sufficiently robust, being potentially suitable "for suing for trial" a non-compliant company. In particular, to grant robustness and verifiability, it is necessary to guarantee availability and quality of LCI (life cycle inventory) data. Other methodological and practical issues can also affect the integration of LCA into policies, such as the following:

1. The use of a consequential versus attributional LCA (depending on the scope of the policy). So far, consequential LCA concepts have been implemented only to a limited extent. In particular, it is worth mentioning the Renewable Energy Directive REDII (EC 2018b) that accounts for indirect land use change;

2. The relationship and integration with other models widely used in policy context (e.g. economic models such as partial equilibrium models or general equilibrium models, or other qualitative/quantitative methods for environmental impact assessment);

3. The need of normalization and possibly weighting factors when using impacts assessment methods addressing different impact categories;

4. The need of defining benchmarks for evaluating policy options (especially in light of using LCA in some label- ling schemes, or to set impacts thresholds beyond which the product is not acceptable in the market).

Despite the recent development of the PEF/OEF, policies and communications are frequently missing specific methodological and data requirements together with key detailed explanation on steps and procedures to be followed when performing a LCA study. The results of the dedicated requirement analysis (SI) indicated an overall lack of strict requirements or methodological guidelines for performing life cycle evaluations. This highlights how LCA should be better integrated in policy making, in a way that also ensures the right balance between the following:

1. Enhancing the comparability of LCA results (by being very prescriptive in data and methodological choices) versus providing the required flexibility (in order to grant the applicability of the LCA to diverse product groups or sectors);

2. Allowing limited assessments for a few impact categories (simplifying the interpretation of the results) versus pushing towards more comprehensive assessments (including a large set of impact categories but more difficult to be assessed jointly);

3. Using only very robust life cycle impact assessment methods (e.g. with regard to Global Warming Potential, as the main used in policies) versus extending to methods able to address more impacts (e.g. 16 environmental impacts as recommended by PEF), ensuring their applicability into policies.

\section{Conclusions}

Life cycle thinking and assessment are progressively moving from academic implementation and ad hoc uses (primarily in-house in large companies) to broader applications in the society. This article presents one of the first systematic review and assessment of the applications of the LCT/LCA/ LCC into policies, with a special focus to the EU context.

Over the last 30 years, there has been an increasing emphasis on integrated approaches in environment policy in the EU. Policies have focused on linkages between environment media (such as air, water and soil) and cross-cutting environment themes (e.g. climate change, biodiversity) that pay more attention to sustainable resource use.

In a growing number of policies, LCT and LCA have been recognised as useful approaches supporting impact assessment, implementation measures, and monitoring needs.

Already in 1990, the Council resolution of 7 May 1990 on waste policy (EC 1990) invited the Commission to submit as soon as possible a proposal for a Community-wide ecolabelling scheme covering the environmental impact during the 
entire life cycle of the product. This resulted in the first EU Regulation regarding Ecolabel (CEC 1991; EC 1992), in which it was evident how the evaluation of the impacts associated to product life cycle is at the core of the label scheme. From the results of the present study it is evident the pivotal role not only of the Ecolabel Regulation (EC 1992, 2010a), but also of the Ecodesign Directive (EC 2005, 2009a). These two policies have been important in the widespread of LCA with regard to products, since a high number of specific documents implementing these policies have been introduced during the years. In addition, recent cutting-edge methodologies (the PEF/OEF) manifest the growing interest in the harmonisation of key methodological choices and data quality requirements in the field of LCA. In the most recent years (from 2016 onwards), the number of policies and communications that are explicitly citing concepts and methods related with life cycle is growing, and the EU policy-making can be considered a frontrunner in the implementation of LCA into policies.

Based on the policies classified in this review, it is evident that the concept of life cycle has been continuously growing in number and relevance of the applications, and it is increasingly cited and envisioned as a relevant element also for future policies. In particular, LCT is very horizontally adopted in key strategic documents for setting of new policies and ambitious targets in the context of the EU Green Deal. However, it was identified that life cycle concepts could be implemented in a more thorough way in policies. In fact, results of a dedicated assessment of life cycle-based requirements in policies indicate a general lack of specific methodological requirements and guidelines for the application of life cycle methodologies (LCA, LCC and PEF/OEF).

Depending on the type of application of policies, even the quality of LCA results can change. For general policies (including strategic document, planning, research programmes), it is still possible to use LCA to a higher level of uncertainty. When LCA is instead applied to specific requirements, it is necessary to specify with a very high level of details the methods and underlying data to be used. The presence of market surveillance authorities of MS could ensure that such requirements are binding enough, demanding for instance compulsory information.

The abovementioned aspects are crucial for any policy makers and require actions by several stakeholders (from methods developer to policy maker) to ensure applicability of LCA to policies. Furthermore, a number of other methodological and practical issues that can affect the integration of LCA into policies can be identified (e.g. the use of consequential or attributional LCA, the need of defining benchmarks, the integration with other models widely used in policy context).

An overall objective that is possible to identify from the performed analysis is the need of moving from general LCT approaches, which have been to date predominant compared to other life cycle approaches, toward more comprehensive uses of LCA (such as, for instance, evaluation of impacts according to the prescription of the Environmental Footprint methods). Among all others, the PEF/OEF methods are worth mentioning, since these represent one of the most relevant initiatives in the field of life cycle assessment in recent years. These methodologies seek to establish a common method to measure and communicate the life cycle environmental performance of products and organisations, and, furthermore, introduced the PEFCRs. Given the wide range of different decision-contexts and sectors, the development of product-/sector-specific criteria, guidelines, and simplified tools would provide an important support for fostering LCA applications, and the PEFCRs are going into this direction. In fact, PEFCRs will support practitioners in focusing on the most important parameters, thus also reducing the time, cost and the expertise required. In general, the main field of action where life cycle was found to be relevant in the EU set of policies referred to product policies. This is evident, for instance, in the relevance of the Ecolabel Regulation and the Ecodesign Directive (and related implementations), as illustrated in the results of this work. The importance of the evaluation of environmental impacts/costs with a life cycle mindset is expected to further grow and the analysis of recent policies and communication indicate that the environmental footprint methods will be strongly considered in the foreseeable future.

Finally, there is the need of collaboration and co-production of knowledge towards harmonisation of life cycle approaches. This should be done in order to ensure that different policies considering life cycle perspectives are coordinated when assessing diverse topics. This implies also additional efforts towards harmonising life cycle methods adopted in different policy contexts which have a life cycle perspective. In this context it is worth mentioning the relevant role of the scientific community, which should keep in mind the policy needs when proposing for instance new impact assessment method. In fact, it would be important to account for robustness, data availability, representativeness, understanding (for non LCA-experts), and verifiability in developing new LC-related results, in view of pave the paths for easier policy implementations.

Our expectation, based on the past experience of using LCT and LCA approaches for policy support, is that the use of life cycle methodologies and related methods and tools in policy support will continue to grow in influence in the foreseeable future and that the environmental performances of MS will be improved by the time of the next review.

Supplementary information The online version contains supplementary material available at https://doi.org/10.1007/s11367-021-01893-2. 
Acknowledgements Beyond the authors, a range of (existing and former) staff members of the European Commission Joint Research Centre have contributed to an increasing use of LCA in EU policies and in laying the foundations of this this work, namely David Pennington, Rana Pant and Fabrice Mathieux. We also acknowledge the support of the Directorate General Environment of the European Commission for partly financing the described activities via the Administrative Arrangements Technical support for the Environmental Footprint and the Life Cycle Data Network (EF4) DG ENV Nº70201/2019/811467/ AA/ENV.B.1.

\section{Declarations}

Declaration of competing interest The authors declare that they have no known competing financial interests or personal relationships that could have appeared to influence the work reported in this paper.

Open Access This article is licensed under a Creative Commons Attribution 4.0 International License, which permits use, sharing, adaptation, distribution and reproduction in any medium or format, as long as you give appropriate credit to the original author(s) and the source, provide a link to the Creative Commons licence, and indicate if changes were made. The images or other third party material in this article are included in the article's Creative Commons licence, unless indicated otherwise in a credit line to the material. If material is not included in the article's Creative Commons licence and your intended use is not permitted by statutory regulation or exceeds the permitted use, you will need to obtain permission directly from the copyright holder. To view a copy of this licence, visit http://creativecommons.org/licenses/by/4.0/.

\section{References}

Ardente F, Mathieux F (2014) Identification and assessment of product's measures to improve resource efficiency: the case-study of an Energy using Product. J Clean Prod 83(15):126-141. https:// doi.org/10.1016/j.jclepro.2014.07.058

Agostini A, Giuntoli J, Marelli L, Amaducci S (2020) Flaws in the interpretation phase of bioenergy LCA fuel the debate and mislead policymakers. Int J Life Cycle Asses 25(1):17-35. https:// doi.org/10.1007/s11367-019-01654-2

Brander M, Tipper R, Hutchison C, Davis G (2008) Technical Paper: Consequential and attributional approaches to LCA: a Guide to policy makers with specific reference to greenhouse gas LCA of biofuels. Technical paper TP-090403-A, Ecometrica Press, London, UK. http://www.globalbioenergy.org/uploads/media/0804_ Ecometrica_-_Consequential_and_attributional_approaches_to_ LCA.pdf. Accessed 9 Dec 2020

CEC (1991) Proposal for a Council Regulation (EEC) on a community award scheme for an eco-label. COM 1991:37

CEC (2001) Green paper on Integrated Product Policy. COM 2001:68

CEC (2003) Communication from the commission to the council and the European parliament. Integrated Product Policy Building on Environmental Life-Cycle Thinking. COM (2003) 302

CEC (2004) Communication from the commission to the council and the European parliament. Stimulating Technologies for Sustainable Development: An Environmental Technologies Action Plan for the European Union. COM (2004) 38

CEC (2005a) Communication from the commission to the council, the European parliament, the European economic and social committee and the committee of the regions. Thematic Strategy on the sustainable use of natural resources. COM (2005) 670
CEC (2005b) Communication from the commission to the council, the European parliament, the European economic and social committee and the committee of the regions. Taking sustainable use of resources forward: A Thematic Strategy on the prevention and recycling of waste. COM (2005) 666

CEC (2005c) Proposal for a Directive of the European parliament and of the council on waste. COM 2005:667

CEC (2008a) Communication from the Commission to the European Parliament, the Council, the European Economic and Social Committee and the Committee of the Regions. Public procurement for a better environment. COM (2008) 400

CEC (2008b) Communication from the Commission to the European Parliament, the Council, the European Economic and Social Committee and the Committee of the Regions on the Sustainable Consumption and Production and Sustainable Industrial Policy Action Plan. COM 2008:397

CEC (2010a) Report from the Commission on indirect land-use change related to biofuels and bioliquids. COM 2010:811

CEC (2010b) Report from the Commission to the council and the European parliament on sustainability requirements for the use of solid and gaseous biomass sources in electricity, heating and cooling. COM 2010:11

CEC (2011a) Communication from the Commission to the European Parliament, the Council, the European Economic and Social Committee and the Committee of the Regions. A resource-efficient Europe - Flagship initiative under the Europe 2020 Strategy COM 201121

CEC (2011b) Communication from the Commission to the European Parliament, the Council, the European Economic and Social Committee and the Committee of the Regions. Roadmap to a Resource Efficient Europe Roadmap to a resource efficient Europe. COM (2011) 571

CEC (2012a) Communication from the Commission to the European Parliament and the Council. Strategy for the sustainable competitiveness of the construction sector and its enterprises. COM (2012) 433

CEC (2012b) Proposal for a Decision of the European Parliament and of the Council on a General Union Environment Action Programme to 2020 Living well, within the limits of our planet COM 2012710

CEC (2012c) Communication from the Commission to the European Parliament, the Council, the European Economic and Social Committee and the Committee of the Regions. Innovating for Sustainable Growth: A Bioeconomy for Europe. COM (2012) 60

CEC (2012d) Communication from the commission to the European parliament, the council, the European economic and social committee and the committee of the regions. A stronger European Union for growth and economic recovery. Industrial Policy communication update. COM (2012) 582

CEC (2012e) Communication from the commission to the European parliament, the council, the European economic and social committee and the committee of the regions. Protecting businesses against misleading marketing practices and ensuring effective enforcement. Review of Directive 2006/114/EC concerning misleading and comparative advertising. COM (2012) 702

CEC (2013a) Communication from the commission to the European parliament and the council. Building the Single Market for Green Products. Facilitating better information on the environmental performance of products and organisations. COM (2013) 196

CEC (2013b) Communication from the commission to the European parliament, the council, the European economic and social committee and the committee of the regions. Setting up a European retail action plan. COM (2013) 36

CEC (2014) Communication from the commission to the European parliament, the council, the European economic and social 
committee and the committee of the regions on resource efficiency opportunities in the building sector. COM 2014:445

CEC (2015a) Communication from the Commission to the European Parliament, the Council, the European Economic and Social Committee and the Committee of the Regions. Closing the loop - An EU action plan for the Circular Economy. COM (2015) 614

CEC (2015b) Communication from the Commission to the European Parliament, the Council, the European Economic and Social Committee and the Committee of the Region. Better Regulation for better results - An EU agenda. COM (2015) 215

CEC (2016a) Communication from the Commission to the European Parliament, the Council, the European Economic and Social Committee and the Committee of the Region and the European investment bank. Accelerating Clean Energy Innovation COM 2016:763

CEC (2016b) Proposal for a Regulation of the European parliament and of the council on the Governance of the Energy Union, amending Directive 94/22/EC, Directive 98/70/EC, Directive 2009/31/EC, Regulation (EC) No 663/2009, Regulation (EC) No 715/2009, Directive 2009/73/EC, Council Directive 2009/119/EC, Directive 2010/31/EU, Directive 2012/27/EU, Directive 2013/30/EU and Council Directive (EU) 2015/652 and repealing Regulation (EU) No 525/2013. COM 2016:759

CEC (2016c) Proposal for a Regulation of the European Parliament and of the Council on the financial rules applicable to the general budget of the Union and amending Regulation (EC) No 2012/2002, Regulations (EU) No 1296/2013, (EU) 1301/2013, (EU) No 1303/2013, EU No 1304/2013, (EU) No 1305/2013, (EU) No 1306/2013, (EU) No 1307/2013, (EU) No 1308/2013, (EU) No 1309/2013, (EU) No 1316/2013, (EU) No 223/2014, (EU) No 283/2014, (EU) No 652/2014 of the European Parliament and of the Council and Decision No 541/2014/EU of the European Parliament and of the Council. COM(2016) 605

CEC (2017a) Communication from the Commission to the European Parliament, the Council, the European Economic and Social Committee and the Committee of the Regions. The EU Environmental Implementation Review: Common challenges and how to combine efforts to deliver better results. COM (2017) 63

CEC (2017b) Communication from the Commission to the European Parliament, the Council, the European Economic and Social Committee and the Committee of the Regions. The role of wasteto-energy in the circular economy. COM (2017) 34

CEC (2018a) Proposal for a Regulation of the European Parliament and of the Council on the establishment of a framework to facilitate sustainable investment. COM 2018:353

CEC (2018b) Proposal for a Regulation of the European parliament and of the council amending Regulation (EU) 2016/1011 on low carbon benchmarks and positive carbon impact benchmarks. COM 2018:355

CEC (2018c) Proposal for a Regulation of the European parliament and of the council establishing the InvestEU Programme. COM 2018:439

CEC (2018d) Communication from the Commission to the European Parliament, the Council, the European Economic and Social Committee and the Committee of the Regions. A sustainable Bioeconomy for Europe: Strengthening the connection between economy, society and the environment. COM (2018) 673

CEC (2018e) communication from the commission to the European parliament, the council, the European economic and social committee and the committee of the regions Europe on the movE. Sustainable Mobility for Europe: safe, connected, and clean. COM (2018) 293

CEC (2019a) Communication from the commission to the European parliament, the European council, the council, the European economic and social committee and the committee of the regions. The European Green Deal COM 2019:640
CEC (2019b) Report from the commission to the European parliament, the council, the European economic and social committee, the committee of the regions and the European investment bank on the Implementation of the Strategic Action Plan on Batteries: building a strategic battery value chain in Europe. COM 2019:176

CEC (2020a) Communication from the commission to the European parliament, the council, the European economic and social committee and the committee of the regions. A new Circular Economy Action Plan For a cleaner and more competitive Europe. COM (2020) 98

CEC (2020b) Communication from the commission to the European parliament, the council, the European economic and social committee and the committee of the region. EU Biodiversity Strategy for 2030 Bringing nature back into our lives. COM (2020) 380

CEC (2020c) Communication from the commission to the European parliament, the council, the European economic and social committee and the committee of the regions. A Farm to Fork Strategy for a fair, healthy and environmentally-friendly food system. COM (2020) 381

CEC (2020d) Communication from the commission to the European parliament, the council, the European economic and social committee and the committee of the regions. Chemicals Strategy for Sustainability Towards a Toxic-Free Environment. COM (2020) 667

CEC (2020e) Proposal for a decision of the European Parliament and of the Council a General Union Environment Action Programme to 2030. COM 2020:652

CEC (2020f) Communication from the commission to the European parliament, the council, the European economic and social committee and the committee of the regions. A new industrial strategy for Europe. COM (2020) 102

CEC (2020g) Communication from the commission to the European parliament, the council, the European economic and social committee and the committee of the regions. A hydrogen strategy for a climate-neutral Europe. COM (2020) 301

Curran MA (1997) Life-cycle based government policies a survey. Int J Life Cycle Assess 2:39. https://doi.org/10.1007/BF02978718

EC (1975) Council Directive 75/442/EEC of 15 July 1975 on waste

EC (1990) Council Resolution of 7 May 1990 on waste policy

EC (1991) Council Decision of 9 September 1991 adopting a specific programme of research and technological development in the field of industrial and materials technologies (1990 to 1994)

EC (1992) Council Regulation (EEC) No 880/92 of 23 March 1992 on a Community eco-label award scheme

EC (1994) European Parliament and Council Directive 94/62/EC of 20 December 1994 on packaging and packaging waste

EC (1998) Directive 98/70/EC of the European Parliament and of the Council of 13 October 1998 relating to the quality of petrol and diesel fuels and amending Council Directive 93/12/EEC

EC (2000) Directive 2000/53/EC of the European Parliament and of the Council of 18 September 2000 on end-of life vehicles

EC (2003) Directive 2003/30/EC of the European Parliament of 8 May 2003 on the promotion of the use of biofuels or other renewable fuels for transport

EC (2005) Directive 2005/32/EC of the European Parliament and of the Council of 6 July 2005 establishing a framework for the setting of ecodesign requirements for energy-using products and amending Council Directive 92/42/EEC and Directives 96/57/EC and 2000/55/EC of the European Parliament and of the Council

EC (2006) Regulation No 1907/2006 of the European Parliament and of the Council of 18 December 2006 concerning the Registration, Evaluation, Authorisation and Restriction of Chemicals $(\mathrm{REACH})$, establishing a European Chemicals Agency, amending 
Directive 1999/45/EC and repealing Council Regulation (EEC) No 793/93 and Commission Regulation (EC) No 1488/94 as well as Council Directive 76/769/EEC and Commission Directives 91/155/EEC, 93/67/EEC, 93/105/EC and 2000/21/EC

EC (2008) Directive 2008/98/EC of the European Parliament and of the Council of 19 November 2008 on waste and repealing certain Directives

EC (2009a) Directive 2009/125/EC of the European Parliament and of the Council of 21 October 2009 establishing a framework for the setting of ecodesign requirements for energy-related products

EC (2009b) Regulation No 1221/2009 of the European Parliament and of the Council of 25 November 2009 on the voluntary participation by organisations in a Community eco-management and audit scheme (EMAS), repealing Regulation (EC) No 761/2001 and Commission Decisions 2001/681/EC and 2006/193/EC

EC (2009c) Directive 2009/30/EC of the European Parliament and of the Council of 23 April 2009 amending Directive 98/70/EC as regards the specification of petrol, diesel and gas-oil and introducing a mechanism to monitor and reduce greenhouse gas emissions and amending Council Directive 1999/32/EC as regards the specification of fuel used by inland waterway vessels and repealing Directive 93/12/EEC

EC (2010a) Regulation No 66/2010 of the European Parliament and of the Council of 25 November 2009 on the EU Ecolabel

EC (2010b) Directive 2010/30/EU of the European Parliament and of the Council of 19 May 2010 on the indication by labelling and standard product information of the consumption of energy and other resources by energy-related products

EC (2011) Regulation No 305/2011 of the European Parliament and of the Council of 9 March 2011 laying down harmonised conditions for the marketing of construction products and repealing Council Directive 89/106/EEC

EC (2013a) Commission Recommendation 2013/179/EU on the use of common methods to measure and communicate the life cycle environmental performance of products and organisations

EC (2014a) Directive 2014/23/EU of the European parliament and of the council of 26 February 2014 on the award of concession contracts

EC (2014b) Directive 2014/24/EU of the European Parliament and of the Council of 26 February 2014 on public procurement and repealing Directive 2004/18/EC

EC (2014c) Directive 2014/25/EU of the European Parliament and of the Council of 26 February 2014 on procurement by entities operating in the water, energy, transport and postal services sectors and repealing Directive 2004/17/EC

EC (2015a) Directive 2015/1513/EU of the European Parliament and of the Council of 9 September 2015 amending Directive 98/70/ EC relating to the quality of petrol and diesel fuels and amending Directive 2009/28/EC on the promotion of the use of energy from renewable sources

EC (2015b) Commission Delegated Regulation (EU) 2015/2462 of 30 October 2015 amending Delegated Regulation (EU) No $1268 / 2012$ on the rules of application of Regulation (EU, Euratom) No 966/2012 of the European Parliament and of the Council on the financial rules applicable to the general budget of the Union

EC (2015c) Regulation (EU, EURATOM) 2015/1929 of the European Parliament and of the Council of 28 October 2015 amending Regulation (EU, Euratom) No 966/2012 on the financial rules applicable to the general budget of the Union

EC (2015d) Council Directive (EU) 2015/652 of 20 April 2015 laying down calculation methods and reporting requirements pursuant to Directive 98/70/EC of the European Parliament and of the Council relating to the quality of petrol and diesel fuels

EC (2017a) Regulation 2017/1951 of the european Parliament and of the Council of 25 October 2017 amending Regulation (EU) No
99/2013 on the European statistical programme 2013-17, by extending it to 2020

EC (2017b) Commission Decision (EU) 2017/1508 of 28 August 2017 on the reference document on best environmental management practice, sector environmental performance indicators and benchmarks of excellence for the food and beverage manufacturing sector under Regulation (EC) No 1221/2009 of the European Parliament and of the Council on the voluntary participation by organisations in a Community eco-management and audit scheme (EMAS)

EC (2017c) Regulation 2017/1369 of the European Parliament and of the Council of 4 July 2017 setting a framework for energy labelling and repealing Directive 2010/30/EU

EC (2018a) Directive 2018/852 of the European Parliament and of the Council of 30 May 2018 amending Directive 94/62/EC on packaging and packaging waste

EC (2018b) Directive 2018/2001 of the European Parliament and of the Council of 11 December 2018 on the promotion of the use of energy from renewable sources

EC (2018c) Decision (EU) 2018/813 of 14 May 2018 on the sectoral reference document on best environmental management practices, sector environmental performance indicators and benchmarks of excellence for the agriculture sector under Regulation (EC) No 1221/2009 of the European Parliament and of the Council on the voluntary participation by organisations in a Community eco-management and audit scheme (EMAS)

EC (2018d) Regulation (EU, Euratom) 2018/1046 of the European Parliament and of the Council of 18 July 2018 on the financial rules applicable to the general budget of the Union, amending Regulations (EU) No 1296/2013, (EU) No 1301/2013, (EU) No 1303/2013, (EU) No 1304/2013, (EU) No 1309/2013, (EU) No 1316/2013, (EU) No 223/2014, (EU) No 283/2014, and Decision No 541/2014/EU and repealing Regulation (EU, Euratom) No $966 / 2012$

EC (2018e) Regulation (EU, Euratom) 2018/1046 of the European Parliament and of the Council of 11 December 2018 on the Governance of the Energy Union and Climate Action, amending Regulations (EC) No 663/2009 and (EC) No 715/2009 of the European Parliament and of the Council, Directives 94/22/EC, 98/70/EC, 2009/31/EC, 2009/73/EC, 2010/31/EU, 2012/27/EU and 2013/30/EU of the European Parliament and of the Council, Council Directives 2009/119/EC and (EU) 2015/652 and repealing Regulation (EU) No 525/2013 of the European Parliament and of the Council

EC (2019a) Directive 2019/1161 of the European Parliament and of the Council of 20 June 2019 amending Directive 2009/33/EC on the promotion of clean and energy-efficient road transport vehicles

EC (2019b) Directive 2019/904 of the European Parliament and of the Council of 5 June 2019 on the reduction of the impact of certain plastic products on the environment

EC (2019c) Commission Decision 2019/62 of 19 December 2018 on the sectoral reference document on best environmental management practices, sector environmental performance indicators and benchmarks of excellence for the car manufacturing sector under Regulation (EC) No 1221/2009 on the voluntary participation by organisations in a Community eco-management and audit scheme (EMAS)

EC (2019d) Commission Decision 2019/63 of 19 December 2018 on the sectoral reference document on best environmental management practices, sector environmental performance indicators and benchmarks of excellence for the electrical and electronic equipment manufacturing sector under Regulation (EC) No 1221/2009 of the European Parliament and of the Council on the voluntary participation by organisations in a Community eco-management and audit scheme (EMAS) 
EC (2019e) Decision (EU) 2019/62 of 19 December 2018 on the sectoral reference document on best environmental management practices, sector environmental performance indicators and benchmarks of excellence for the car manufacturing sector under Regulation (EC) No 1221/2009 on the voluntary participation by organisations in a Community eco-management and audit scheme (EMAS)

EC (2019f) Decision (EU) 2019/63 of 19 December 2018 on the sectoral reference document on best environmental management practices, sector environmental performance indicators and benchmarks of excellence for the electrical and electronic equipment manufacturing sector under Regulation (EC) No 1221/2009 of the European Parliament and of the Council on the voluntary participation by organisations in a Community eco-management and audit scheme (EMAS)

EC (2019g) Regulation (EU) 2020/852 of the European Parliament and of the Council of 27 November 2019 amending Regulation (EU) 2016/1011 as regards EU Climate Transition Benchmarks, EU Paris-aligned Benchmarks and sustainability-related disclosures for benchmarks

EC (2020a) Regulation (EU) 2020/852 of the European Parliament and of the Council of 18 June 2020 on the establishment of a framework to facilitate sustainable investment, and amending Regulation (EU) 2019/2088

EC (2020b) Commission Decision (EU) 2020/519 of 3 April 2020 on the sectoral reference document on best environmental management practices, sector environmental performance indicators and benchmarks of excellence for the waste management sector under Regulation (EC) No 1221/2009 on the voluntary participation by organisations in a Community eco-management and audit scheme (EMAS)

EPA (United States Environmental Protection Agency) (2020) The Energy Independence and Security Act. https://www.epa.gov/ laws-regulations/summary-energy-independence-and-securityact. Accessed 3 Oct 2020

EU (2020a) European commission Life cycle costing. https://ec.europa. eu/environment/gpp/lcc.htm Accessed 13 Oct 2020

EU (2020b) European Platform on Life Cycle Assessment (LCA). https://ec.europa.eu/environment/ipp/lca.htm\#: :text=The\% 20European\%20Commission's\%20project\%20The,underlying\% 20 data $\% 20$ and $\% 20$ methodological\%20needs. Accessed 6 Oct 2020

EU (2020c) Environmental Footprint. https://eplca.jrc.ec.europa.eu// EnvironmentalFootprint.html. Accessed 16 Nov 2020

EU (2020d) Types of EU law. https://ec.europa.eu/info/law/law-making-process/types-eu-law_en. Accessed 7 Dec 2020

EU (2020e) Regulations, Directives and other acts. https://europa.eu/ european-union/law/legal-acts_en\#decisions. Accessed 7 December 2020

EU (2020f) EU Monitor. Recommendation. https://europa.eu/europ ean-union/law/legal-acts_en\#decisions. Accessed 7 Dec 2020

EU (2020g) EU Monitor. Legal instruments. https://www.eumonitor. $\mathrm{eu} / 9353000 / 1 / \mathrm{j} 9 \mathrm{vvik} 7 \mathrm{~m} 1 \mathrm{c} 3 \mathrm{gy} x \mathrm{p} / \mathrm{vh} 75 \mathrm{mdhkg} 4 \mathrm{~s} 0$. Accessed 7 Dec 2020

EU (2020h). Results and deliverables of the Environmental Footprint pilot phase. https://ec.europa.eu/environment/eussd/smgp/ PEFCR_OEFSR_en.htm. Accessed 9 Feb 2021

EUR-Lex (2020a) Summaries of EU Legislation. https://eur-lex. europa.eu/legal-content/EN/TXT/?uri=LEGISSUM\%3Arec ommendations. Accessed 7 Dec 2020

EUR-Lex (2020b) Access to European Union law. https://eur-lex.europa.eu/ homepage.html. Accessed 28 September 2020

EUR-Lex (2020c) Legal acts - statistics. https://eur-lex.europa.eu/stati stics/legal-acts/2020/legislative-acts-statistics-by-type-of-act. html. Accessed 7 Dec 2020
Güereca LP, Ochoa-Sosa R, Gilbert HE, Suppen-Reynaga N (2015) Life cycle assessment in Mexico: overview of development and implementation. Int J Life Cycle Assess 20:311-317. https://doi.org/10.1007/s11367-014-0844-9

Hunkeler D, Yasui I, Yamamoto R (1998) LCA in Japan: policy and progress. Int J Life Cycle Assess 3:124-130. https://doi.org/10. 1007/BF02978820

ISO (International Organization for Standardization) (1997) ISO 14040. Environmental management - Life cycle assessment Principles and framework. Geneva, Switzerland

ISO (International Organization for Standardization) (2006a) ISO 14040. Environmental management - Life cycle assessment Principles and framework. Geneva, Switzerland

ISO (International Organization for Standardization) (2006b) ISO 14044. Environmental management - Life cycle assessment Requirements and guidelines. Geneva, Switzerland

ISO (International Organization for Standardization) (2017) ISO 15686-5. Buildings and constructed assets - Service life planning - Part 5: life cycle costing. Geneva, Switzerland

Kituyi E (2004) Integrating life cycle approaches to African national development policies: considering the institutional dimension of industrial ecology. Prog in Ind Ecol, an Int J 1(1-3):229-244. https://ecommons.aku.edu/eastafrica_eai/43/ Accessed 9 Dec 2020

Lazarevic D, Buclet N, Brandt N (2012) The application of life cycle thinking in the context of European waste policy. J Clean Prod 29:199-207. https://doi.org/10.1016/j.jclepro.2012.01.030

Lehmann A, Finkbeiner M, Broadbent C, Balzer T (2015) Policy options for life cycle assessment deployment in legislation. In: Sonnemann G., Margni M. (eds) Life Cycle Management. LCA Compendium - The Complete World of Life Cycle Assessment. Springer, Dordrecht, pp 213-224. https://link.springer. com/chapter/10.1007\%2F978-94-017-7221-1_15. Accessed 11 February 2021

Mathieux F, Ardente F, Bobba S (2020) Ten years of scientific support for integrating circular economy requirements in the EU ecodesign directive: overview and lessons learnt. Procedia CIRP 90:137-142. https://doi.org/10.1016/j.procir.2020.02.121

Maia de Souza D, Braga T, Brito de Figueirêdo MC, Matsuura MISF, Dias FRT, Ugaya CML (2017) Life cycle thinking in Brazil: challenges and advances towards a more comprehensive practice. Int J Life Cycle Assess 22:462-465. https://doi.org/10.1007/ s11367-016-1234-2

Pennington D, Wolf M, Bersani R, Pretato U (2007) Overcoming barriers to the broader implementation of life cycle thinking in business and public administration. Int $\mathrm{J}$ of Life Cycle Assess 12(7):458-460. https://doi.org/10.1065/lca2007.07.355

Perera O, Morton B, Perfrement T (2009) Life cycle costing: a question of value A white paper from IISD. International Institute for Sustainable Development, Winnipeg, Mantioba, Canada

Prado-Lopez V, Wender BA, Seager TP, Laurin L, Chester M, Arslan E (2016) Tradeoff evaluation improves comparative life cycle assessment: a photovoltaic case study. J IndEcol 20(4):710-718. https://doi.org/10.1111/jiec.12292

Reed DL (2012) Life-cycle Assessment in Government Policy in the United States. PhD diss. University of Tennessee. https://trace. tennessee.edu/cgi/viewcontent.cgi? article $=2502 \&$ context $=$ utk graddiss Accessed 26 August 2020

Sala S (2019) Life cycle assessment and evaluation of solutions towards sustainable development goals. In: Filho WL (ed) Encyclopedia of the UN Sustainable Development Goals. Springer, ISSN, pp 2523-7403

Sala S, Beylot A, Corrado S, Crenna E, Sanyé-Mengual E, Secchi M (2019) Indicators and Assessment of the environmental impact of EU consumption.Consumption and Consumer Footprintfor assessing and monitoring EU policies with Life Cycle 
Assessment, Luxembourg: Publications Office of the European Union,ISBN 978-92-79-99672-6, https://doi.org/10.2760/ 403263

Sala S, Reale F, Cristobal Garcia J, Marelli L, Pant R (2016) Life cycle assessment for the impact assessment of policies. Luxembourg (Luxembourg): Publications Office of the European Union, EUR28380EN

Schenck R (2009) The business case for life cycle assessment in US policy and legislation. American Centre for Life Cycle Assess. https://lcacenter.org/ Accessed 25 August 2020

Seidel C (2016) The application of life cycle assessment to public policy development. Int J Life Cycle Assess 21(3):337-348. https:// doi.org/10.1007/s11367-015-1024-2

Sonnemann G, Gemechu ED, Sala S, Schau EM, Allacker K, Pant R, Adibi N, Valdivia S (2018) Life cycle thinking and the use of LCA in policies around the world Life Cycle Assess 429-463 https://doi.org/10.1007/978-3-319-56475-3_18

United Nations (UN) (2015) Transforming Our World: the 2030 Agenda for Sustainable Development. https://sustainabledevelopment.un. org/post2015/transformingourworld. Accessed 3 September 2020

UNEP (United Nations Environment Program) (2015) Regional Strategy on Sustainable Consumption and Production (SCP) for the
10YFP implementation in Latin-America and the Caribbean (2015-2022) https://sustainabledevelopment.un.org/index.php? page $=$ view $\&$ type $=400 \& n r=1444 \&$ menu $=35$. Accessed 6 October 2020 .

Valdivia S, Sonnemann G, Mila i Canals L, (2017) LCA mainstreaming conditions in Latin America based on learnings from 2005 to 2014. Int J Life Cycle Assess 22:485-491. https://doi.org/10. 1007/s11367-016-1142-5

Vázquez-Rowe I, Marvuglia A, Rege S, Benetto E (2014) Applying consequential LCA to support energy policy: land use change effects of bioenergy production. Science of the Total Environ 472:78-89. https://doi.org/10.1016/j.scitotenv.2013.10.097

Wardenaar T, van Ruijven T, Beltran AM, Vad K, Guinée J, Heijungs R (2012) Differences between LCA for analysis and LCA for policy: a case study on the consequences of allocation choices in bio-energy policies. Int J Life Cycle Assess 17:1059-1067. https://doi.org/10.1007/s11367-012-0431-X

Publisher's Note Springer Nature remains neutral with regard to jurisdictional claims in published maps and institutional affiliations. 